\title{
Isomerism in Benzenetricarboxylates: Variations in the Formation of Coordination Polymers with Uranyl Ion
}

\author{
Pierre Thuéry, ${ }^{*}, \dagger$ Youssef Atoini ${ }^{\ddagger}$ and Jack Harrowfield ${ }^{*}+$ \\ ${ }^{\dagger}$ Université Paris-Saclay, CEA, CNRS, NIMBE, 91191 Gif-sur-Yvette, France \\ ‡Université de Strasbourg, ISIS, 8 allée Gaspard Monge, 67083 Strasbourg, France
}

\begin{abstract}
A series of uranyl ion complexes with fully or partially deprotonated 1,2,4-benzenetricarboxylic acid $\left(\mathrm{H}_{3} \mathrm{btc}\right)$ and involving either organic countercations or additional metal cations has been synthesized under solvo-hydrothermal conditions. The complexes $\left[\mathrm{PPh}_{4}\right]\left[\mathrm{UO}_{2}(\mathrm{btc})\right]$ (1) and $\left[\mathrm{PPh}_{4}\right]_{2}\left[\left(\mathrm{UO}_{2}\right)_{2}(\mathrm{Hbtc})_{3}\right] \cdot \mathrm{H}_{2} \mathrm{O}$ (2) crystallize as monoperiodic coordination polymers, while $\left[\mathrm{PPh}_{3} \mathrm{Me}\right]\left[\mathrm{UO}_{2}(\mathrm{btc})\right] \cdot \mathrm{H}_{2} \mathrm{O}(\mathbf{3})$ is a diperiodic network with the fes topology. Monoperiodic organization is also found in $\left[\mathrm{H}_{2} \mathrm{DABCO}\right]\left[\left(\mathrm{UO}_{2}\right)_{2}(\mathrm{btc})_{2}\right] \cdot 2 \mathrm{H}_{2} \mathrm{O}(4)(\mathrm{DABCO}$ $=$ 1,4-diazabicyclo[2.2.2] octane), but $[\mathrm{Hquin}]_{2}\left[\left(\mathrm{UO}_{2}\right)_{5}(\mathrm{btc})_{4}\right] \cdot 2 \mathrm{H}_{2} \mathrm{O}(\mathbf{5})$ (quin = quinuclidine) is a triperiodic framework. Incorporation of azamacrocyclic complexes of d-block metal cations gives $\left[\left(\mathrm{UO}_{2}\right)_{2}(\mathrm{btc})_{2} \mathrm{Ni}(\mathrm{cyclam})\right]$ (6) and $\left[\left(\mathrm{UO}_{2}\right)_{2}(\mathrm{btc})_{2} \mathrm{Cu}\left(R, S-\mathrm{Me}_{6}\right.\right.$ cyclam) $)$ (7) (cyclam = 1,4,8,11-tetraazacyclotetradecane, $R, S$-Me ${ }_{6}$ cyclam $=$ $7(R), 14(S)-5,5,7,12,12,14$-hexamethylcyclam), two diperiodic networks with the same $\mathrm{V}_{2} \mathrm{O}_{5}$ topology, but differing in the diaxial bonding of the $3 \mathrm{~d}$ metal cation, either to uranyl oxo groups or to carboxylato groups, respectively. Triperiodic polymerization occurs in $\left[\mathrm{UO}_{2} \mathrm{Ag}_{2}(\mathrm{Hbtc})_{2}\left(\mathrm{H}_{2} \mathrm{O}\right)_{2}\right] \quad$ (8) and $\left[\left(\mathrm{UO}_{2}\right)_{2} \mathrm{Ag}_{2}(\mathrm{btc})_{2}\left(\mathrm{CH}_{3} \mathrm{CN}\right)_{1.5}\left(\mathrm{H}_{2} \mathrm{O}\right)_{0.43}\right] \cdot 1.5 \mathrm{H}_{2} \mathrm{O}$ (9), with both oxo- and carboxylato-bonding of the bridging silver(I) cations. The isomorphous complexes $\left[\mathrm{UO}_{2} \mathrm{Rb}(\mathrm{btc})\left(\mathrm{H}_{2} \mathrm{O}\right)\right](\mathbf{1 0})$ and $\left[\mathrm{UO}_{2} \mathrm{Cs}(\mathrm{btc})\left(\mathrm{H}_{2} \mathrm{O}\right)\right]$ (11) also crystallize as triperiodic frameworks with bonding of the alkali metal cations to oxo and carboxylato groups. In 10 and 11, uranyl cations and $\mathrm{btc}^{3-}$ ligands alone give a 2-fold interpenetrated triperiodic framework with utp topology. Emission spectra in the solid state display the usual vibronic fine structure for $\mathbf{1}-\mathbf{5}, \mathbf{1 0}$ and 11, while uranyl emission is quenched in 7. Photoluminescence quantum yields range from 1.3 to $17.4 \%$, less than that for solid $\mathrm{UO}_{2}\left(\mathrm{NO}_{3}\right)_{2} \cdot 6 \mathrm{H}_{2} \mathrm{O}$, except for 1 which has the unusually large value of $35 \%$. Comparisons are drawn with previous studies of uranyl ion complexes of all known benzenetricarboxylate isomers.
\end{abstract}




\section{INTRODUCTION}

A quite frequently encountered feature of the crystal structures of uranyl ion complexes of polycarboxylates is the presence of diperiodic polymer arrays of true or distorted honeycomb forms involving linking of hexagonal bipyramidal $\left[\mathrm{UO}_{2}\left(\mathrm{O}_{2} \mathrm{CR}\right)_{3}\right]^{-}$units. ${ }^{1,2}$ In seeking the formation of triperiodic arrays defining potential reaction cavities, various methods of overcoming this tendency have been found, one of the simplest being exemplified in the complexes of 1,2,3- and 1,2,4-benzene tricarboxylates ("hemimellitate" and "trimellitate", respectively), where the symmetry of the carboxylate array is incompatible with the threefold symmetric link required for a true honeycomb form and, more importantly, interactions between the carboxylates cause them to twist out of the plane of the benzene ring, thus favouring triperiodic linking. ${ }^{3,4}$ In the case of the 1,3,5 isomer, neither restriction applies and although structural data for its uranium complexes are limited, ${ }^{5-7}$ near-coplanarity of all three carboxylate groups with the benzene ring is observed.

Although the 1,2,4 isomer of benzene tricarboxylate (denoted $\mathrm{btc}^{3-}$ hereafter) in particular is a rather commonly used assembling ligand, present in about 160 crystal structures reported in the Cambridge Structural Database (CSD, Version 5.41), ${ }^{8,9}$ most of them involving d-block metal cations, it has seldom been considered for the synthesis of uranyl-based coordination polymers (or uranyl-organic species ${ }^{10-13}$ ) although other benzenepolycarboxylic acids are very commonly found in this context. The first examples reported, $\left[\mathrm{H}_{3} \mathrm{O}\right]\left[\left(\mathrm{UO}_{2}\right)_{6} \mathrm{O}(\mathrm{OH})(\mathrm{btc})_{2}(\mathrm{Hbtc})_{2}\left(\mathrm{H}_{2} \mathrm{O}\right)_{2}\right] \cdot 6 \mathrm{H}_{2} \mathrm{O}, \quad$ and $\quad\left[\mathrm{H}_{2} \mathrm{NMe}_{2}\right]\left[\left(\mathrm{UO}_{2}\right)_{2} \mathrm{O}(\mathrm{btc})\right] \cdot \mathrm{H}_{2} \mathrm{O}$, crystallized as triperiodic frameworks and both of them included bridging hydroxo and/or oxo anions resulting in the formation of tetranuclear uranyl clusters as secondary building units (SBUs). ${ }^{3}$ Subsequently, the complex $\left[\mathrm{UO}_{2}(\mathrm{Hbtc})\left(\mathrm{H}_{2} \mathrm{O}\right)_{2}\right]_{2} \cdot 2 \mathrm{H}_{2} \mathrm{O}$, containing the incompletely deprotonated acid in a simple dimeric form involving carboxylate bridging only, was 
characterized. ${ }^{4}$ More recently and while the present work was in progress, two more triperiodic species were reported, [DMPD] $\left[\mathrm{H}_{3} \mathrm{O}\right]\left[\mathrm{H}_{2} \mathrm{NMe}_{2}\right]_{2}\left[\left(\mathrm{UO}_{2}\right)_{5} \mathrm{O}_{3}(\mathrm{OH})(\mathrm{HCOO})(\mathrm{btc})_{2}\right] \cdot \mathrm{DMF} \cdot \mathrm{H}_{2} \mathrm{O}$ and $\left[\mathrm{NEt}_{4}\right]_{2}\left[\left(\mathrm{UO}_{2}\right)_{2}(\mathrm{btc})_{2}\left(\mathrm{H}_{2} \mathrm{O}\right)\right] \cdot 5 \mathrm{H}_{2} \mathrm{O}$ (where DMPD is 1,1-dimethylpyrrolidinium and DMF is $N, N$-dimethylformamide), the first of which displays pentanuclear oxo/hydroxo-bridged SBUs. ${ }^{14}$ No other actinide ion complex with $\mathrm{H}_{3}$ btc is known, but, among f element ions, some lanthanide(III) complexes have been described. ${ }^{15}$ In all the known structurally characterized uranyl ion complexes, dihedral angles between the carboxylate groups and the benzene ring vary considerably but at least one is seen to involve twisting around the $\mathrm{C}-\mathrm{CO}_{2}$ bond so as to give a dihedral angle close to $90^{\circ}$, indicating, in the light of a number of our previous investigations, that it should be possible to influence the crystal structure significantly by variations in factors influencing the carboxylate dispositions.

For some time, we have been interested in the structural modifications that can be brought about in uranyl polycarboxylate complexes synthesized under solvo-hydrothermal conditions through the systematic introduction of additional complexed metallic cations, or of organic or inorganic counterions of variable charge, shape and bulkiness, such as phosphonium cations or metal azamacrocycle complexes, among others. ${ }^{16-20}$ Applying this strategy to $\mathrm{H}_{3}$ btc has allowed the isolation of 11 homo- and heterometallic complexes which have been characterized by their crystal structure and, in most cases, their emission spectrum in the solid state, and are described herein. The additional species involved are the phosphonium cations $\mathrm{PPh}_{4}{ }^{+}$and $\mathrm{PPh}_{3} \mathrm{Me}^{+}$, the ammonium cations $\mathrm{H}_{2} \mathrm{DABCO}^{2+}$ and $\mathrm{Hquin}^{+}(\mathrm{DABCO}=1,4-$ diazabicyclo[2.2.2]octane and quin $=$ quinuclidine $), \mathrm{Ni}(\text { cyclam })^{2+}$ and $\left[\mathrm{Cu}\left(R, S-\mathrm{Me}_{6} \mathrm{cyclam}\right)\right]^{2+}$ $($ cyclam $=1,4,8,11$-tetraazacyclotetradecane, $R, S$-Me 6 cyclam (meso isomer $)=7(R), 14(S)$ 5,5,7,12,12,14-hexamethylcyclam), and the metal cations $\mathrm{Ag}^{+}, \mathrm{Rb}^{+}$and $\mathrm{Cs}^{+}$. It is notable that in no case are oxo or hydroxo bridges present, uranyl ions being thus isolated and not included within polynuclear SBUs. All these complexes are polymeric and they display a variety of 
periodicities, from one to three, and of connectivities of the different species present. The two isomorphous complexes including alkali metal cations in particular are intricate triperiodic frameworks in which uranyl cations and ligands alone generate a 2-fold interpenetrated triperiodic net.

\section{EXPERIMENTAL SECTION}

Syntheses. Caution! Uranium is a radioactive and chemically toxic element, and uranium-containing samples must be handled with suitable care and protection.

$\mathrm{UO}_{2}\left(\mathrm{NO}_{3}\right)_{2} \cdot 6 \mathrm{H}_{2} \mathrm{O}$ (RP Normapur, 99\%) was purchased from Prolabo. 1,2,4benzenetricarboxylic anhydride (Hbtca) was obtained from Aldrich. [Ni(cyclam) $\left.\left(\mathrm{NO}_{3}\right)_{2}\right]$ and $\left[\mathrm{Cu}\left(R, S-\mathrm{Me}_{6}\right.\right.$ cyclam $\left.)\left(\mathrm{NO}_{3}\right)_{2}\right]$ were synthesized as previously described. ${ }^{17,19}$ Elemental analyses were performed by MEDAC Ltd. at Chobham, UK or Service Chromato-Masse Microanalyse (UMR 8076) of Université Paris-Saclay. For all syntheses, the mixtures in demineralized water/organic solvent were placed in $10 \mathrm{~mL}$ tightly closed glass vessels and heated at $140{ }^{\circ} \mathrm{C}$ under autogenous pressure.

$\left[\mathrm{PPh}_{4}\right]\left[\mathrm{UO}_{2}(\right.$ btc $\left.)\right](\mathbf{1}) . \mathrm{Hbtca}(19 \mathrm{mg}, 0.10 \mathrm{mmol}), \mathrm{UO}_{2}\left(\mathrm{NO}_{3}\right)_{2} \cdot 6 \mathrm{H}_{2} \mathrm{O}(35 \mathrm{mg}, 0.07 \mathrm{mmol})$, and $\mathrm{PPh}_{4} \mathrm{Br}(42 \mathrm{mg}, 0.10 \mathrm{mmol})$ were dissolved in water $(0.6 \mathrm{~mL})$ and $\mathrm{DMF}(0.2 \mathrm{~mL})$. Yellow crystals of complex 1 were obtained within one week (27 mg, 47\% yield based on U). Anal. Calcd for $\mathrm{C}_{33} \mathrm{H}_{23} \mathrm{O}_{8} \mathrm{PU}$ : C, 48.54; H, 2.84. Found: C, 48.27; H, 2.78\%.

$\left[\mathrm{PPh}_{4}\right]_{2}\left[\left(\mathrm{UO}_{2}\right)_{2}(\mathrm{Hbtc})_{3}\right] \cdot \mathrm{H}_{2} \mathrm{O}$ (2). Hbtca $(19 \mathrm{mg}, 0.10 \mathrm{mmol}), \mathrm{UO}_{2}\left(\mathrm{NO}_{3}\right)_{2} \cdot 6 \mathrm{H}_{2} \mathrm{O}(35 \mathrm{mg}$, $0.07 \mathrm{mmol})$, and $\mathrm{PPh}_{4} \mathrm{Br}(42 \mathrm{mg}, 0.10 \mathrm{mmol})$ were dissolved in water $(0.8 \mathrm{~mL})$ and acetonitrile (0.2 mL). Yellow crystals of complex 2 were obtained within three weeks (15 mg, 23\% yield based on $\mathrm{U}$ ). Elemental analysis results indicate the presence of four water molecules in excess of the quantity found from crystal structure determination. Anal. Calcd for $\mathrm{C}_{75} \mathrm{H}_{54} \mathrm{O}_{23} \mathrm{P}_{2} \mathrm{U}_{2}+4$ $\mathrm{H}_{2} \mathrm{O}: \mathrm{C}, 46.60 ; \mathrm{H}, 3.23$. Found: C, 46.39; H, 3.28\%. 
$\left[P P h_{3} M e\right]\left[\mathrm{UO}_{2}(b t c)\right] \cdot \mathrm{H}_{2} \mathrm{O}(3)$. Hbtca $(19 \mathrm{mg}, 0.10 \mathrm{mmol}), \mathrm{UO}_{2}\left(\mathrm{NO}_{3}\right)_{2} \cdot 6 \mathrm{H}_{2} \mathrm{O}(35 \mathrm{mg}, 0.07$ mmol), and $\mathrm{PPh}_{3} \mathrm{MeBr}(36 \mathrm{mg}, 0.10 \mathrm{mmol})$ were dissolved in water $(0.8 \mathrm{~mL})$ and $\mathrm{DMF}(0.2$ $\mathrm{mL}$ ). Yellow crystals of complex 3 were obtained in low yield within three days.

$\left[\mathrm{H}_{2} \mathrm{DABCO}\right]\left[\left(\mathrm{UO}_{2}\right)_{2}(b t c)_{2}\right] \cdot 2 \mathrm{H}_{2} \mathrm{O}$ (4). Hbtca $(19 \mathrm{mg}, 0.10 \mathrm{mmol}), \mathrm{UO}_{2}\left(\mathrm{NO}_{3}\right)_{2} \cdot 6 \mathrm{H}_{2} \mathrm{O}(35$ $\mathrm{mg}, 0.07 \mathrm{mmol})$, and DABCO $(12 \mathrm{mg}, 0.11 \mathrm{mmol})$ were dissolved in water $(0.8 \mathrm{~mL})$ and acetonitrile $(0.2 \mathrm{~mL})$. Yellow crystals of complex 4 were obtained within one week $(22 \mathrm{mg}$, 57\% yield based on $\mathrm{U}$ ). Anal. Calcd for $\mathrm{C}_{24} \mathrm{H}_{24} \mathrm{~N}_{2} \mathrm{O}_{18} \mathrm{U}_{2}$ : C, 26.10; H, 2.19; N, 2.54. Found: C, 26.64; H, 2.67; N, 2.97\%.

[Hquin $]_{2}\left[\left(\mathrm{UO}_{2}\right)_{5}(\mathrm{btc})_{4}\right] \cdot 2 \mathrm{H}_{2} \mathrm{O}(5) . \mathrm{Hbtca}(19 \mathrm{mg}, 0.10 \mathrm{mmol}), \mathrm{UO}_{2}\left(\mathrm{NO}_{3}\right)_{2} \cdot 6 \mathrm{H}_{2} \mathrm{O}(35 \mathrm{mg}$, $0.07 \mathrm{mmol})$, and quinHCl (15 $\mathrm{mg}, 0.10 \mathrm{mmol})$ were dissolved in water $(0.8 \mathrm{~mL})$ and acetonitrile $(0.2 \mathrm{~mL})$. Yellow crystals of complex 5 were obtained within three days (10 $\mathrm{mg}, 29 \%$ yield based on U). Anal. Calcd for $\mathrm{C}_{50} \mathrm{H}_{44} \mathrm{~N}_{2} \mathrm{O}_{36} \mathrm{U}_{5}: \mathrm{C}, 24.62 ; \mathrm{H}, 1.82 ; \mathrm{N}, 1.15$. Found: $\mathrm{C}, 24.20 ; \mathrm{H}$, $2.66 ; \mathrm{N}, 1.39 \%$.

$\left[\left(\mathrm{UO}_{2}\right)_{2}(\text { btc })_{2} \mathrm{Ni}(\mathrm{cyclam})\right]$ (6). Hbtca (19 mg, $\left.0.10 \mathrm{mmol}\right), \mathrm{UO}_{2}\left(\mathrm{NO}_{3}\right)_{2} \cdot 6 \mathrm{H}_{2} \mathrm{O}(35 \mathrm{mg}, 0.07$ mmol), and $\left[\mathrm{Ni}(\right.$ cyclam $\left.)\left(\mathrm{NO}_{3}\right)_{2}\right](20 \mathrm{mg}, 0.05 \mathrm{mmol})$ were dissolved in water $(0.8 \mathrm{~mL})$ and acetonitrile $(0.2 \mathrm{~mL})$. Orange crystals of complex 6 were obtained in low yield within three weeks.

$\left[\left(\mathrm{UO}_{2}\right)_{2}(\mathrm{btc})_{2} \mathrm{Cu}\left(\mathrm{R}, \mathrm{S}-\mathrm{Me}_{6} \mathrm{cyclam}\right)\right]$ (7). Hbtca (19 mg, $\left.0.10 \mathrm{mmol}\right), \mathrm{UO}_{2}\left(\mathrm{NO}_{3}\right)_{2} \cdot 6 \mathrm{H}_{2} \mathrm{O}(35$ $\mathrm{mg}, 0.07 \mathrm{mmol})$, and $\left[\mathrm{Cu}\left(R, S-\mathrm{Me}_{6}\right.\right.$ cyclam $\left.)\left(\mathrm{NO}_{3}\right)_{2}\right](24 \mathrm{mg}, 0.05 \mathrm{mmol})$ were dissolved in water $(0.8 \mathrm{~mL})$ and acetonitrile $(0.2 \mathrm{~mL})$. Purple crystals of complex 7 were obtained overnight (19 mg, $42 \%$ yield based on U). Anal. Calcd for $\mathrm{C}_{34} \mathrm{H}_{42} \mathrm{CuN}_{4} \mathrm{O}_{16} \mathrm{U}_{2}: \mathrm{C}, 31.36 ; \mathrm{H}, 3.25 ; \mathrm{N}, 4.30$. Found: C, 31.02; H, 3.08; N, 4.29\%.

$\left[\mathrm{UO}_{2} \mathrm{Ag}_{2}(\mathrm{Hbtc})_{2}\left(\mathrm{H}_{2} \mathrm{O}\right)_{2}\right]$ (8). Hbtca $(19 \mathrm{mg}, 0.10 \mathrm{mmol}), \mathrm{UO}_{2}\left(\mathrm{NO}_{3}\right)_{2} \cdot 6 \mathrm{H}_{2} \mathrm{O}(35 \mathrm{mg}, 0.07$ mmol), and $\mathrm{AgNO}_{3}(34 \mathrm{mg}, 0.20 \mathrm{mmol})$ were dissolved in water $(0.9 \mathrm{~mL})$. Yellow crystals of complex 8 were obtained in low yield within two months. 
$\left[\left(\mathrm{UO}_{2}\right)_{2} \mathrm{Ag}_{2}(\mathrm{btc})_{2}\left(\mathrm{CH}_{3} \mathrm{CN}\right)_{1.5}\left(\mathrm{H}_{2} \mathrm{O}\right)_{0.43}\right] \cdot 1.5 \mathrm{H}_{2} \mathrm{O}$ (9). Hbtca $(19 \mathrm{mg}, 0.10 \mathrm{mmol})$, $\mathrm{UO}_{2}\left(\mathrm{NO}_{3}\right)_{2} \cdot 6 \mathrm{H}_{2} \mathrm{O}(35 \mathrm{mg}, 0.07 \mathrm{mmol})$, and $\mathrm{AgNO}_{3}(34 \mathrm{mg}, 0.20 \mathrm{mmol})$ were dissolved in water $(0.8 \mathrm{~mL})$ and acetonitrile $(0.2 \mathrm{~mL})$. Yellow crystals of complex 9 were obtained in low yield within three days.

$\left[\cup \mathrm{O}_{2} \mathrm{Rb}(\mathrm{btc})\left(\mathrm{H}_{2} \mathrm{O}\right)\right]$ (10) and $\left[\mathrm{UO}_{2} \mathrm{Cs}(\mathrm{btc})\left(\mathrm{H}_{2} \mathrm{O}\right)\right]$ (11). Hbtca (19 mg, $\left.0.10 \mathrm{mmol}\right)$, $\mathrm{UO}_{2}\left(\mathrm{NO}_{3}\right)_{2} \cdot 6 \mathrm{H}_{2} \mathrm{O}(35 \mathrm{mg}, 0.07 \mathrm{mmol})$, and $\mathrm{RbNO}_{3}(29 \mathrm{mg}, 0.20 \mathrm{mmol})$, or $\mathrm{CsNO}_{3}(39 \mathrm{mg}$, $0.20 \mathrm{mmol})$ were dissolved in water $(0.8 \mathrm{~mL})$ and acetonitrile $(0.2 \mathrm{~mL})$. Yellow crystals of complexes 10 and 11 were obtained within three days (23 and $24 \mathrm{mg}, 57$ and 55\% yield based on $\mathrm{U}$ for $\mathbf{1 0}$ and 11, respectively). Elemental analysis results indicate that some acetonitrile is retained in the isolated compounds. Anal. Calcd for $\mathrm{C}_{9} \mathrm{H}_{5} \mathrm{O}_{9} \mathrm{RbU}+0.5 \mathrm{CH}_{3} \mathrm{CN}(\mathbf{1 0})$ : C, 19.98; H, 1.09. Found: $\mathrm{C}, 20.07 ; \mathrm{H}, 1.64 \%$. Anal. Calcd for $\mathrm{C}_{9} \mathrm{H}_{5} \mathrm{CsO}_{9} \mathrm{U}+1.5 \mathrm{CH}_{3} \mathrm{CN}$ (11): C, 20.90; H, 1.39. Found: C, 20.89; H, 1.69\%.

Crystallography. The data were collected at 100(2) K on a Bruker D8 Quest diffractometer equipped with an Incoatec Microfocus Source (I $\mu$ S 3.0 Mo) and a PHOTON III area detector, and operated through the APEX3 software, ${ }^{21}$ except for those for compounds 6 and 7, which were collected at 100(2) K on a Nonius Kappa-CCD area detector diffractometer ${ }^{22}$ using graphite-monochromated Mo K $\alpha$ radiation $(\lambda=0.71073 \AA)$. The crystals were mounted into glass capillaries or on Mitegen micromounts with a protective coating of Paratone-N oil (Hampton Research). The data were processed with SAINT ${ }^{23}$ (or HKL2000 ${ }^{24}$ for 6 and 7). Absorption effects were corrected empirically with the program $\operatorname{SADABS}^{25,26}$ (SCALEPACK $^{24}$ for 6 and 7). All structures were solved by intrinsic phasing with SHELXT, ${ }^{27}$ expanded by subsequent difference Fourier synthesis and refined by full-matrix least-squares on $F^{2}$ with SHELXL, ${ }^{28}$ using the ShelXle interface. ${ }^{29}$ All non-hydrogen atoms were refined with anisotropic displacement parameters. When present, the hydrogen atoms bound to oxygen and 
nitrogen atoms were retrieved from difference Fourier maps, except in the cases indicated below, and, when possible, they were refined with restraints. The carbon-bound hydrogen atoms were introduced at calculated positions and were treated as riding atoms with an isotropic displacement parameter equal to 1.2 times that of the parent atom ( 1.5 for $\mathrm{CH}_{3}$, with optimized geometry). Crystal data and structure refinement parameters are given in Table 1. The molecular plots were drawn with ORTEP-3, ${ }^{30}$ and the polyhedral representations with VESTA. ${ }^{31}$ The topological analyses and nodal representations were made with ToposPro. ${ }^{32}$ Special details are as follows.

Complex 2. In both ligands (one of them with inversion symmetry), the uncomplexed carboxylic group is disordered over two sites. In the ligand in which these positions are not related by symmetry, they have been refined with occupancy parameters constrained to sum to unity. In the centrosymmetric ligand, the disordered group was given an occupancy factor of 0.5. The free water molecule $(\mathrm{O} 13)$ was given an occupancy parameter of 0.5 , both so as to take into account its closeness to the disordered group in the centrosymmetric ligand, and to retain an acceptable displacement parameter. Restraints on bond lengths and displacement parameters were applied in the disordered groups. The hydrogen atoms of carboxylic groups and the water molecule were not found.

Complex 5. The hydrogen atom bound to N1 was introduced at a calculated position and was treated as a riding atom with an isotropic displacement parameter equal to 1.2 times that of N1. The hydrogen atoms of the water molecule were neither found, nor introduced. Restraints have been applied for one bond length in the counterion and for the displacement parameters of two carboxylate oxygen atoms and of all the atoms of the counterion. Large voids indicate the presence of other, unresolved solvent molecules. 
Complex 7. The hydrogen atoms bound to nitrogen atoms were introduced at calculated positions and were treated as riding atoms with an isotropic displacement parameter equal to 1.2 times that of the parent atom.

Complex 9. The Ag3 counterion is disordered over two positions which have been refined with occupancy parameters constrained to sum to unity. The attached acetonitrile and water molecules were given occupancy parameters accordingly. This part of the structure required the use of restraints and cannot be considered as determined with great accuracy. The hydrogen atoms of the water molecules (one of them with half-occupancy) were not found.

Complexes 10 and 11. The water molecule (O9) is at hydrogen bonding distance from its image by symmetry, and its hydrogen atoms (not found) are thus necessarily disordered.

Luminescence Measurements. Emission spectra were recorded on solid samples using a Horiba-Jobin-Yvon IBH FL-322 Fluorolog 3 spectrometer equipped with a $450 \mathrm{~W}$ xenon arc lamp, double-grating excitation and emission monochromators $(2.1 \mathrm{~nm} / \mathrm{mm}$ of dispersion; 1200 grooves $/ \mathrm{mm}$ ) and a TBX-04 single photon-counting detector. The powdered compounds were pressed to the wall of a quartz tube, and the measurements were performed using the right-angle mode. An excitation wavelength of $420 \mathrm{~nm}$, a commonly used point although only part of a broad manifold, was used in all cases and the emission was monitored between 450 and 600 $\mathrm{nm}$. The quantum yield measurements were performed by using an absolute photoluminescence quantum yield spectrometer Hamamatsu Quantaurus C11347 and exciting the samples between 300 and $400 \mathrm{~nm}$. 
Table 1. Crystal Data and Structure Refinement Details

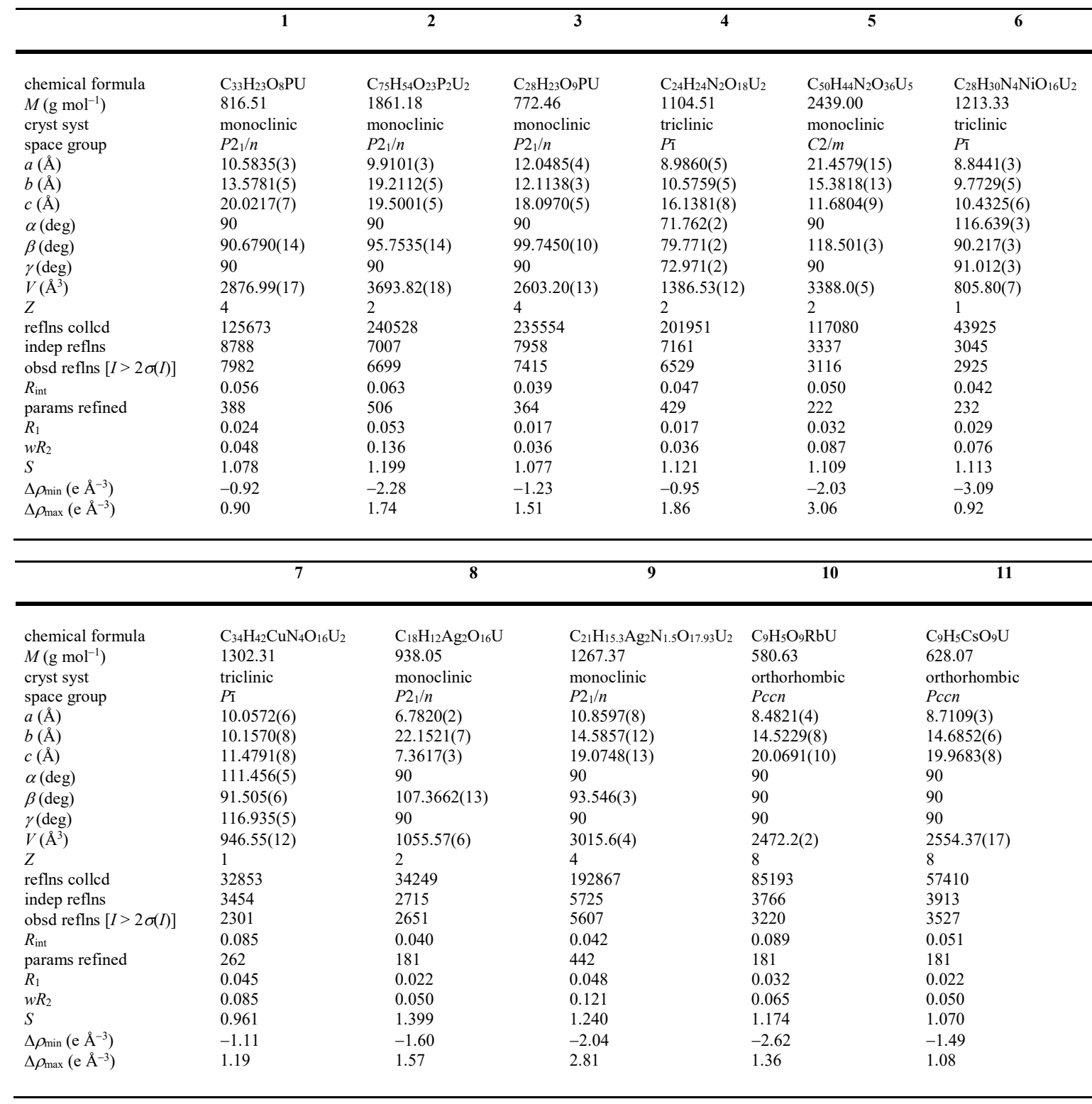

\section{RESULTS AND DISCUSSION}

Crystals of all complexes were grown under solvo-hydrothermal conditions, except for complex 8 for which conditions were purely hydrothermal, at a temperature of $140{ }^{\circ} \mathrm{C}$, and the crystals were deposited directly from the pressurized and heated reaction mixtures and not as a result of subsequent cooling, their presence being detected by visual inspection of the transparent vessels. Interestingly, although in none of the present syntheses were products 
containing hydroxo/oxo oligomers derived from uranyl ion hydrolysis obtained, under slightly milder conditions but with final slow cooling, crystallisation of a species containing pentameric oligomers has been shown to occur. ${ }^{14}$ Although both acetonitrile and DMF were systematically tested as organic solvents in most cases, acetonitrile was generally more successful, since it allowed crystallization of complexes 2, 4-7, and 9-11, only $\mathbf{1}$ and $\mathbf{3}$ having been obtained with DMF. Neither the organic solvents, nor any of their possible hydrolysis products are present in the final species, except for acetonitrile which is retained as a ligand on silver(I) in complex 9. One of the uncertainties commonly associated with solvothermal syntheses in general is the relationship between the composition of the isolated crystals and that of the reaction mixture. An obvious variation in procedure which we and others have found successful for the avoidance of the formation of hydroxo/oxo oligomers as part of anionic uranyl ion carboxylato complexes is to use the acid or its anhydride, as here, rather than, say, its sodium salt as the carboxylate source but even with just a small excess (beyond molar 1:1 = 3:1 carboxylate/uranium) of the acid as in the present syntheses, this does have the disadvantage that complexes, such as $\mathbf{2}$ and $\mathbf{8}$ can be isolated in which deprotonation of the acid is incomplete. Such incomplete ionization has the potential to block the formation of anionic species (with a carboxylate/uranium ratio of 3:1) and thus our objective of incorporating structure-directing counterions but fortunately its influence appears to be slight. Thus, while it is known ${ }^{4}$ that the use of high molar ratios of acid/uranium between 10:1 and 5:1 gives rise to a simple dimeric complex of the dianion of 1,2,4-benzene tricarboxylic acid where the ligand/uranium ratio is $1: 1$, in all the present syntheses anionic polymers are present in the isolated crystals as a result of variations in the ligand/uranium ratio. In complexes $1,3,4,6,7,9,10$ and 11 , where the trianion only is present, this ratio is $1: 1$, while in complex $\mathbf{5}$, where again the trianion is present, the ratio is $4: 5$ and in complexes $\mathbf{2}$ and $\mathbf{8}$, where the dianion is present, the ratios are $3: 2$ and 2:1, respectively. 
In order to avoid a cumbersome and repetitive description of uranyl coordination geometry in each case, we shall just indicate here that the coordination environment is either pentagonal bipyramidal (complexes $\mathbf{1}, \mathbf{3}-\mathbf{7}$ and $\mathbf{9})$ or hexagonal bipyramidal $(\mathbf{2}, \mathbf{8}, \mathbf{1 0}$ and $\mathbf{1 1})$ with only one occurrence of the less common square bipyramidal geometry in one cation of 5 . The U-O bond lengths do not depart from their usual values, the ranges over all the series being 1.748(6)-1.783(3) $\AA$ for oxo groups, 2.397(3)-2.527(3) $\AA$ for $\kappa^{2} O, O^{\prime}$-chelating carboxylate groups, and 2.290(4)-2.417(3) $\AA$ for monodentate or bridging carboxylate groups. The $\mathrm{O}=\mathrm{U}=\mathrm{O}$ angle varies in the range of $176.41(18)-180^{\circ}$, the uranyl group thus not departing much from linearity.

Three complexes were obtained with phosphonium counterions, $\left[\mathrm{PPh}_{4}\right]\left[\mathrm{UO}_{2}(\mathrm{btc})\right](\mathbf{1})$, $\left[\mathrm{PPh}_{4}\right]_{2}\left[\left(\mathrm{UO}_{2}\right)_{2}(\mathrm{Hbtc})_{3}\right] \cdot \mathrm{H}_{2} \mathrm{O}(\mathbf{2})$, and $\left[\mathrm{PPh}_{3} \mathrm{Me}\right]\left[\mathrm{UO}_{2}(\mathrm{btc})\right] \cdot \mathrm{H}_{2} \mathrm{O}(\mathbf{3})$, the difference between $\mathbf{1}$ and 2 being due to the use of a different organic cosolvent, DMF or acetonitrile, respectively, which may result in different acidity of the solutions. The unique uranyl ion in $\mathbf{1}$ is $\kappa^{2} O, O^{\prime}-$ chelated by one carboxylate group (4-membered ring) of one ligand, chelated by the two carboxylate groups in 1,2 positions of another ligand (7-membered ring), and bound to a fifth carboxylate oxygen donor from a third ligand (Figure 1). The $\mathrm{btc}^{3-}$ ligand is bound to three metal cations, with the 1-, 2- and 4-carboxylate groups being monodentate, bridging in $\mu_{2-}$ $\kappa^{1} O: \kappa^{1} O^{\prime}$ mode, and chelating, respectively, and both cation and anion are thus 3 -coordinated (3-c) nodes. The coordination polymer formed is monoperiodic only and directed along [100], and it can be considered as involving the alternation of fused 8- and 16-membered diuranocyclic units. The planar ribbon-like chains are arranged in herringbone fashion when viewed down the chain axis, and they are separated by rows of $\mathrm{PPh}_{4}^{+}$counterions. The latter are loosely associated with one another, with no P...P distance shorter than $8.3 \AA$, and no phenyl embrace interaction $^{33}$ is apparent. Calculation of short contacts with PLATON ${ }^{34}$ indicates that only one 

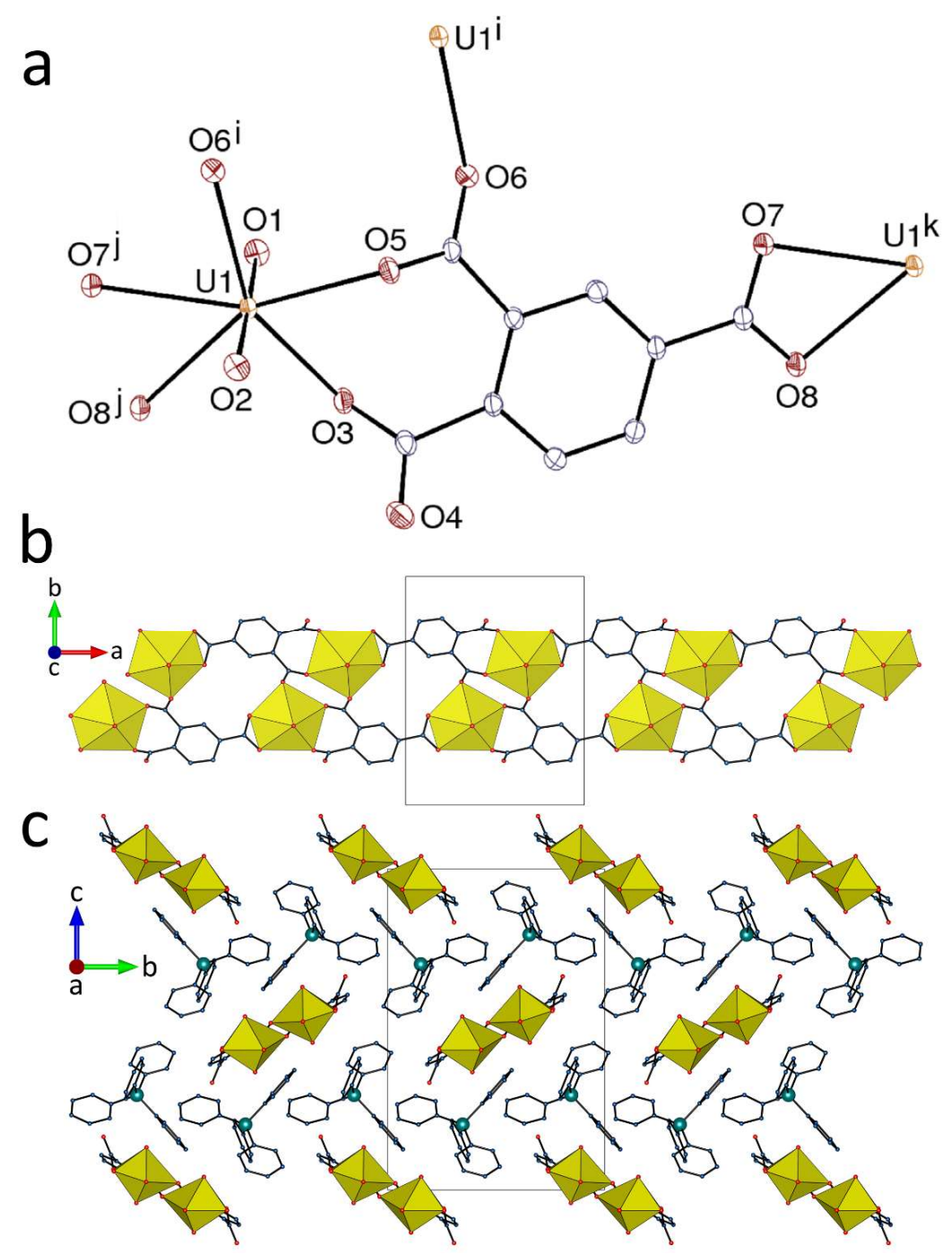

Figure 1. (a) View of compound 1. Displacement ellipsoids are drawn at the $50 \%$ probability level. Counterions and hydrogen atoms are omitted. Symmetry codes: $\mathrm{i}=1-x, 1-y, 1-z ; \mathrm{j}=x+1, y, z ; \mathrm{k}=x-1, y, z$. (b) View of the monoperiodic coordination polymer with uranium coordination polyhedra colored yellow. (c) Packing with chains viewed end-on.

possibly significant $\pi$-stacking interaction, which involves the btc ${ }^{3-}$ ligand and $\mathrm{PPh}_{4}{ }^{+}$, may be present [centroid $\cdots$ centroid distance $4.1373(15) \AA$, dihedral angle $22.50(13)^{\circ}$ ]. However, the interactions most conspicuously apparent on the Hirshfeld surface (HS), ${ }^{35}$ calculated using

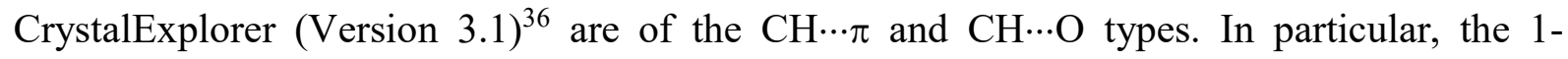
carboxylate group is an acceptor of three $\mathrm{CH} \cdots \mathrm{O}$ bonds, two of them from the same $\mathrm{PPh}_{4}{ }^{+}$ aromatic ring. The latter hydrogen bonding interactions ${ }^{37,38}$ are extremely common in 
carboxylate complexes and they will not be discussed in more detail here. The Kitaigorodski packing index (KPI, calculated with PLATON ${ }^{34}$ ) is 0.69 , the structure having no significant porosity.

The unique uranyl cation in complex $\mathbf{2}$ is $\kappa^{2} O, O^{\prime}$-chelated by three carboxylate groups, while in each of the two independent, disordered $\mathrm{Hbtc}^{2-}$ ligands (one of them centrosymmetric) the two carboxylate groups are chelating, and the carboxylic group is not coordinated (Figure 2). In the non-centrosymmetric ligand, the carboxylic group is in the 1 position, while it is in

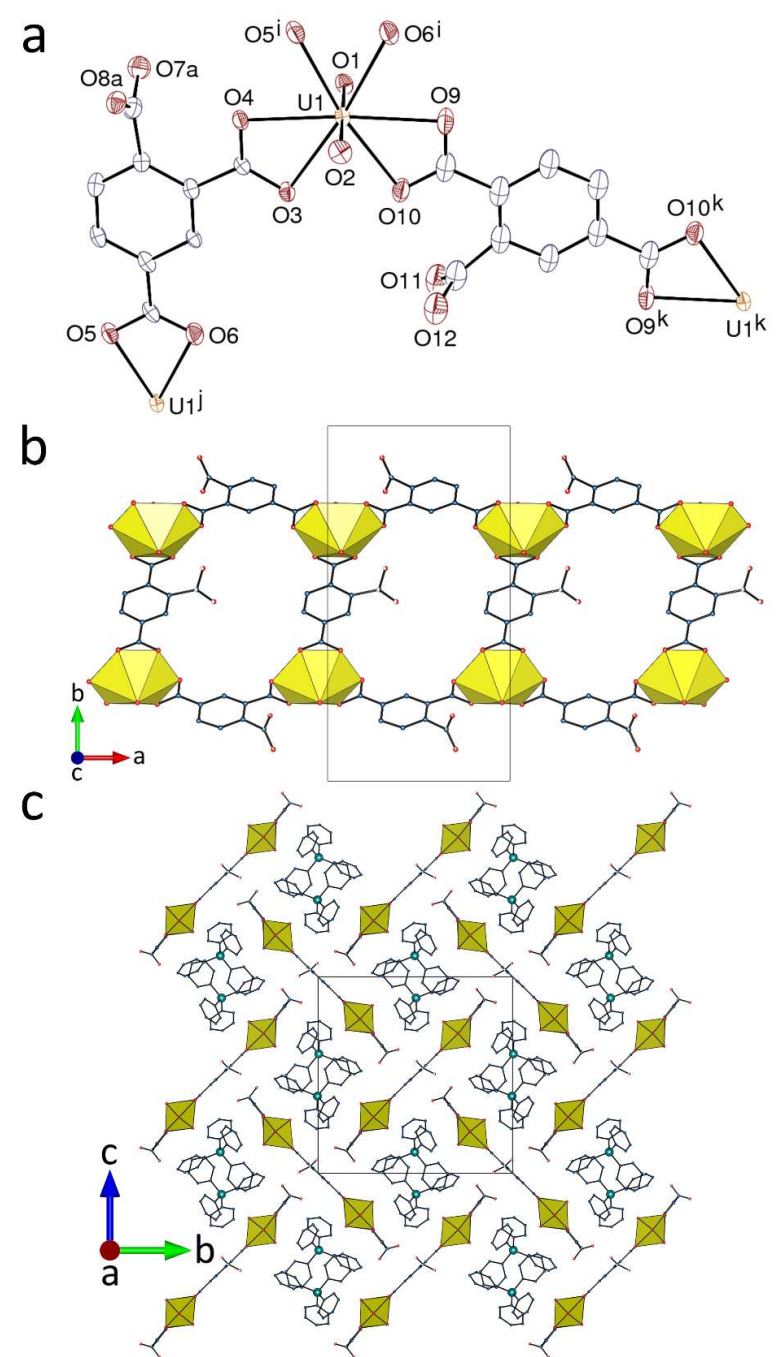

Figure 2. (a) View of compound 2. Displacement ellipsoids are drawn at the $30 \%$ probability level. Counterions, solvent molecules, and hydrogen atoms are omitted, and only one position of the disordered carboxylic groups is shown. Symmetry codes: $\mathrm{i}=x+1, y, z ; \mathrm{j}=x-1, y, z ; \mathrm{k}=1-x,-y, 2-z$. (b) View of the monoperiodic coordination polymer. (c) Packing with chains viewed end-on. 
the 2 position in the centrosymmetric ligand, so that the latter is a linear bridge while the former is slightly curved. A monoperiodic coordination polymer parallel to [100] is formed here also, but the different metal/ligand stoichiometry results in a different topology in which the metal cations are 3-c nodes and the ligands are simple links. The ladderlike chains formed by fusion of 34-membered tetrauranocyclic units are planar, with the linearly bridging ligands as rungs and the curved ones on the sides. Here also, the chains are arranged in a herringbone fashion when viewed down the chain axis. Although the carboxylic protons have not been found, carboxylic oxygen atoms of neighbouring chains are at hydrogen bonding distances from one another. Zigzag rows of $\mathrm{PPh}_{4}{ }^{+}$cations are located within the channels formed, but here the cations are involved in offset sextuple phenyl embrace, ${ }^{33}$ with alternate P...P distances of 6.22 and $6.75 \AA$. There are also two possible $\pi$-stacking interactions between $\mathrm{Hbtc}^{2-}$ and $\mathrm{PPh}_{4}^{+}$

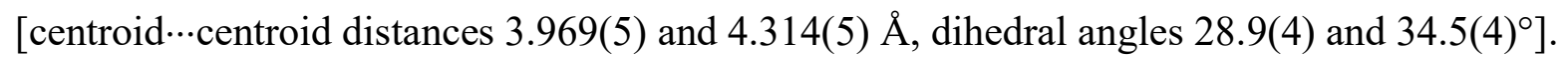

Replacement of $\mathrm{PPh}_{4}^{+}$by $\mathrm{PPh}_{3} \mathrm{Me}^{+}$in complex 3 results in a different geometry, although the stoichiometry and the connectivity of the uranyl cation and btc ${ }^{3-}$ ligand are identical to those found in $\mathbf{1}$, i.e. the uranyl ion is chelated by one carboxylate group, chelated by the two carboxylate groups in 1,2 positions of another ligand, and bound to a fifth carboxylate donor from a third ligand (Figure 3). Both metal and ligand are 3-c nodes, but the

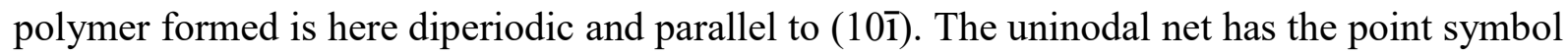
$\left\{4.8^{2}\right\}$ and the common fes topological type. The planar sheets are widely separated by layers of $\mathrm{PPh}_{3} \mathrm{Me}^{+}$counterions, the latter being arranged in rows parallel to [010] containing cations interacting mainly through a single $\pi$-stacking interaction with each neighbour [centroid $\cdots$ centroid distance $3.8011(13) \AA$, dihedral angle $16.23(11)^{\circ}$ ], the P..P distance being $6.57 \AA$. Examination of the HS evidences several $\mathrm{CH} \cdots \mathrm{O}$ hydrogen bonds. In particular, the methyl group of $\mathrm{PPh}_{3} \mathrm{Me}^{+}$points toward the anionic layer and makes a hydrogen bond with a 


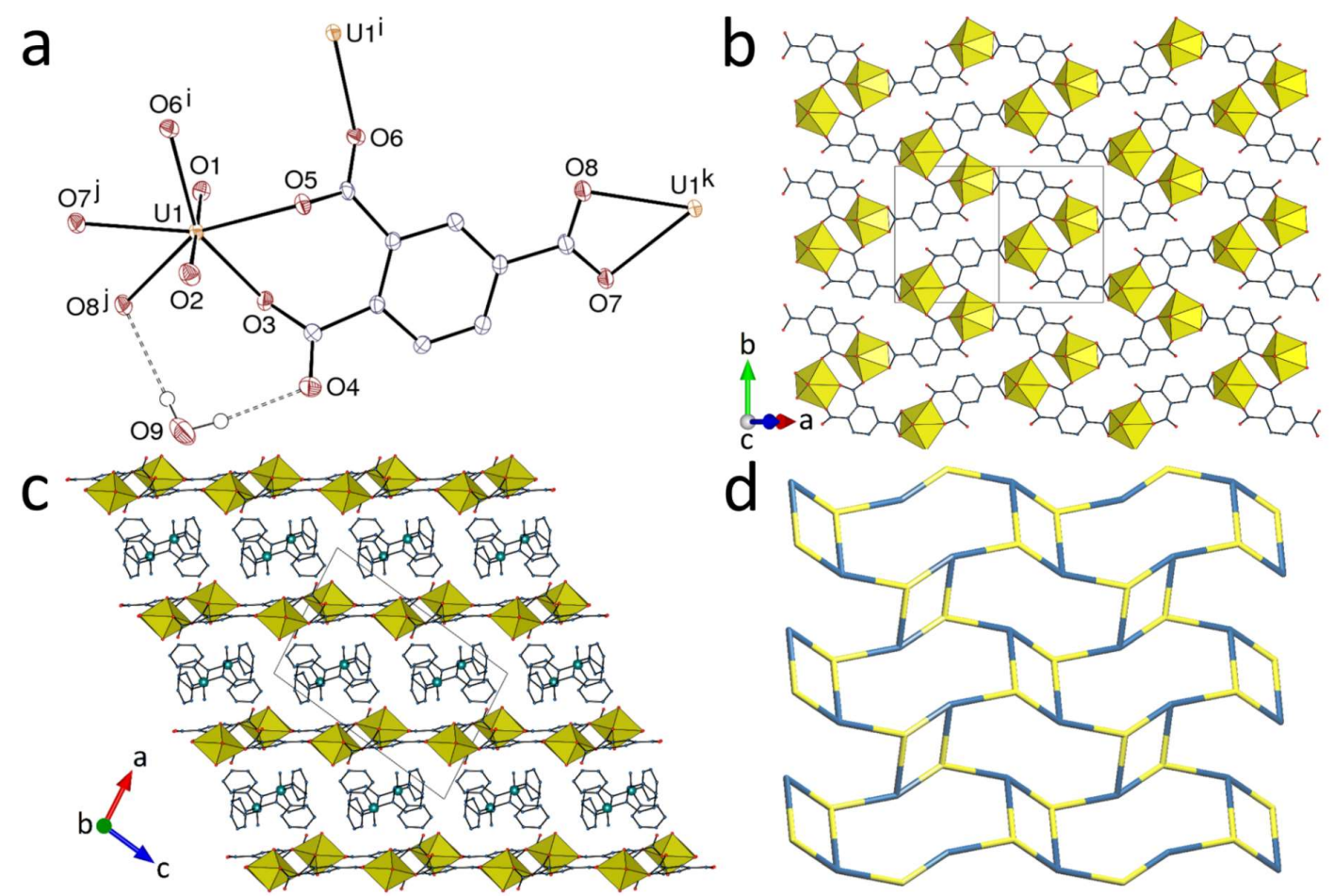

Figure 3. (a) View of compound 3. Displacement ellipsoids are drawn at the $50 \%$ probability level. Counterions and carbon-bound hydrogen atoms are omitted and hydrogen bonds are shown as dashed lines. Symmetry codes: $\mathrm{i}=-x, 2-y, 1-z ; \mathrm{j}=x+1 / 2,3 / 2-y, z+1 / 2 ; \mathrm{k}=x-1 / 2,3 / 2-y, z-1 / 2$. (b) View of the diperiodic coordination polymer. (c) Packing with layers viewed edge-on. (d) Nodal representation of the diperiodic assembly (uranium nodes, yellow; btc ${ }^{3-}$ nodes, dark blue; same orientation as in part b).

uranyl oxo group $\left[\mathrm{C} \cdots \mathrm{O} 3.243(2) \AA, \mathrm{C}-\mathrm{H} \cdots \mathrm{O} 167^{\circ}\right]$, and another with the free water molecule $\left[\mathrm{C} \cdots \mathrm{O} 3.142(3) \AA, \mathrm{C}-\mathrm{H} \cdots \mathrm{O} 172^{\circ}\right]$. The latter is itself a hydrogen bond donor toward two carboxylate oxygen atoms bound to the same uranyl group [O‥O 2.825(3) and 3.030(3) $\AA$, O$\mathrm{H} \cdots \mathrm{O} 168(3)$ and $\left.160(4)^{\circ}\right]$, thus forming a ring with the graph set descriptor ${ }^{39,40} R_{2}^{2}(8)$. The packing is compact and the KPI of 0.71 indicates that no significant free space is present.

The complex $\left[\mathrm{H}_{2} \mathrm{DABCO}\right]\left[\left(\mathrm{UO}_{2}\right)_{2}(\mathrm{btc})_{2}\right] \cdot 2 \mathrm{H}_{2} \mathrm{O}$ (4) has the same metal/ligand stoichiometry as $\mathbf{1}$ and $\mathbf{3}$, and the two independent uranyl ions and $\mathrm{btc}^{3-}$ ligands have the same connectivity as in these cases (Figure 4). The monoperiodic polymer formed, parallel to [010], 


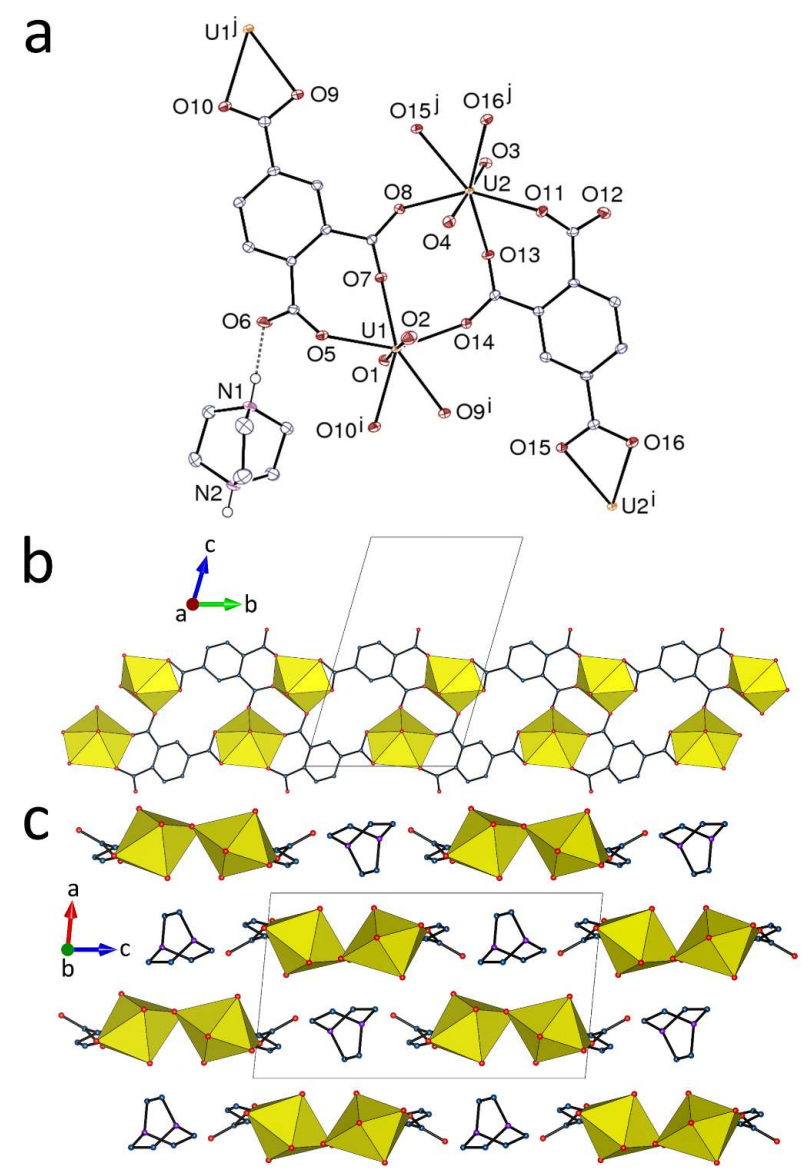

Figure 4. (a) View of compound 4. Displacement ellipsoids are drawn at the 50\% probability level. Carbon-bound hydrogen atoms are omitted and the hydrogen bond is shown as a dashed line. Symmetry codes: $\mathrm{i}=x, y-1, z ; \mathrm{j}=$ $x, y+1, z$. (b) View of the monoperiodic coordination polymer. (c) Packing with chains viewed end-on.

is very close to that in $\mathbf{1}$, but, while the chains in $\mathbf{1}$ are centrosymmetric, the absence of a symmetry element in the chains in $\mathbf{4}$ endows them with chirality (both enantiomers being however present in the centrosymmetric crystal). Associated with this, the 8-membered diuranocyclic units present now have a conformation of a boat type, as distinct from the chairlike form found in $\mathbf{1}$. Layers parallel to (100) are formed, in which polymeric chains alternate with rows of $\mathrm{H}_{2} \mathrm{DABCO}^{2+}$ cations, all being connected through hydrogen bonding of the cations to uncomplexed carboxylate oxygen atoms (O6 and O12) [N... 2.624(3) and 2.704(3) $\AA, \mathrm{N}-$ $\mathrm{H} \cdots \mathrm{O} 176(5)$ and $\left.153(4)^{\circ}\right]$. The two free water molecules are hydrogen bonded to one another and to carboxylate groups from different layers, and a possible parallel-displaced $\pi$-stacking 
interaction links one aromatic ring of $\mathrm{btc}^{3-}$ to its counterpart in the next layer [centroid $\cdots$ centroid distance 3.8391(18) $\AA$, dihedral angle $0.03(15)^{\circ}$, slippage $1.44 \AA$ ]. Adjacent layers along [100] are offset so as to be stacked in bump-to-hollow fashion, resulting in a compact packing (KPI $0.75)$.

Replacing DABCO by quinuclidine as a base, all other parameters being unchanged, has a very notable effect on the outcome. The complex thus obtained, $[\text { Hquin }]_{2}\left[\left(\mathrm{UO}_{2}\right)_{5}(\mathrm{btc})_{4}\right] \cdot 2 \mathrm{H}_{2} \mathrm{O}(\mathbf{5})$, has a metal/ligand stoichiometry only slightly different from that of $\mathbf{4}$, but the connectivity is considerably modified. Of the two independent uranyl cations present, one (U1) is located on a site with $2 / m$ symmetry and bound to only four equatorial carboxylate oxygen atoms, while the other (U2) is $\kappa^{2} O, O^{\prime}$-chelated by one carboxylate group and bound to three more carboxylate oxygen atoms from three different ligands (Figure 5). Both $\mathrm{U} 1$ and $\mathrm{U} 2$ are thus 4-c nodes, and the unique $\mathrm{btc}^{3-}$ ligand is a 5-c node since the 2-carboxylate group is chelating and the 1,4-carboxylates are bridging in the $\mu_{2}-\kappa^{1} O: \kappa^{1} O^{\prime}$ mode. The resulting coordination polymer is a 3-nodal, 4,4,5-c triperiodic framework with the point symbol $\left\{4^{2} \cdot 8^{2} \cdot 10^{2}\right\}\left\{4^{4} \cdot 6^{2}\right\} 4\left\{4^{6} \cdot 6^{4}\right\}$. Elongated channels with a section of $\sim 4 \times 16 \AA^{2}$, running along [001] and intersecting smaller channels with a section of $\sim 4 \times 7 \AA^{2}$ along [100], contain the counterions. The badly resolved Hquin ${ }^{+}$cation, with mirror symmetry, is hydrogen bonded to a free water molecule, and not to a carboxylate group, although the water molecule in turn may be involved in weak, bridging hydrogen bond donation to a uranyl oxo group. The KPI of the overall structure is 0.61 , but it is only 0.46 when counterions and solvent molecules are excluded, thus showing the open nature of the framework. 


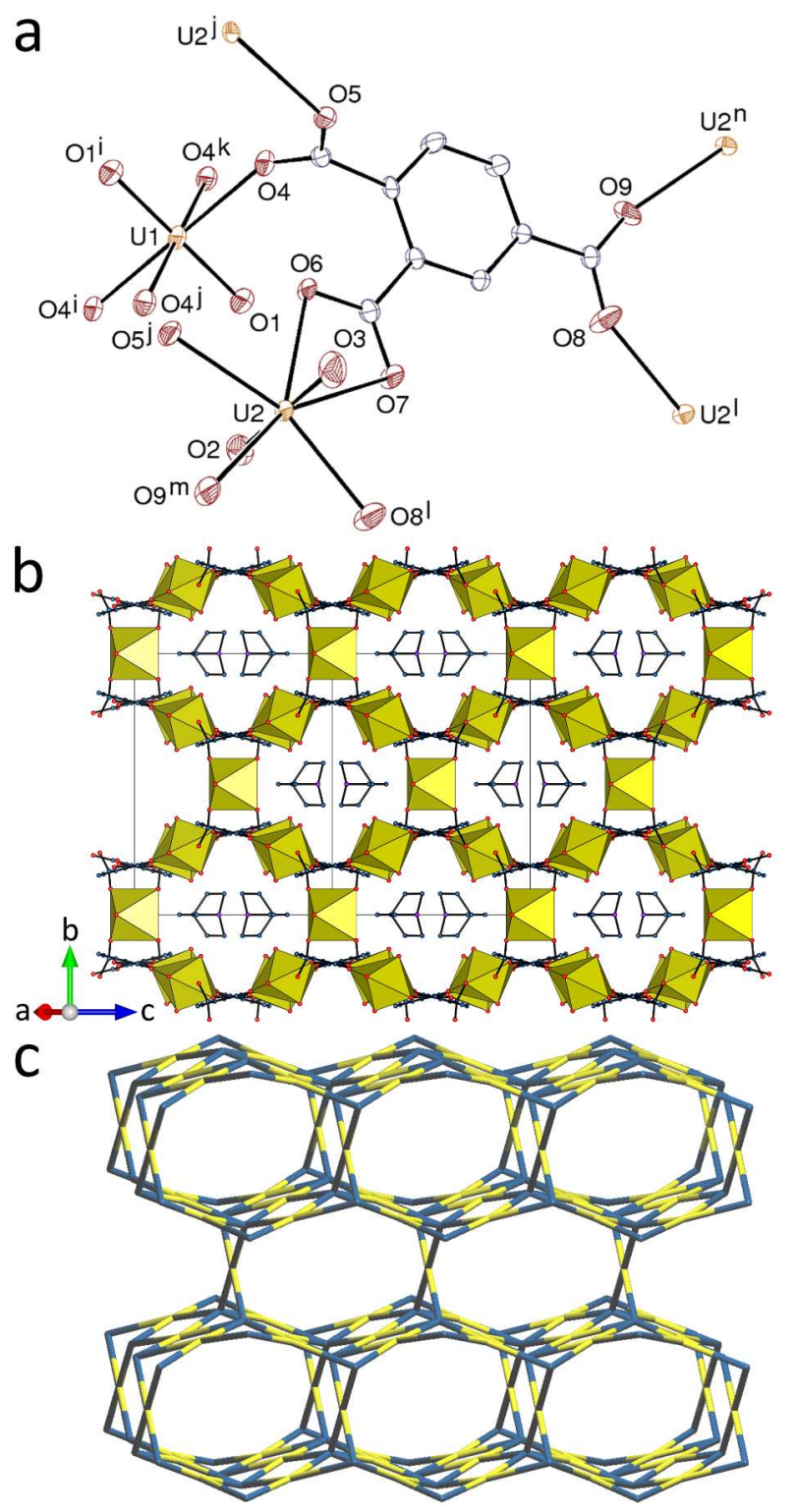

Figure 5. (a) View of compound 5. Displacement ellipsoids are drawn at the 50\% probability level. Counterions, solvent molecules and hydrogen atoms are omitted. Symmetry codes: $\mathrm{i}=1-x, 1-y, 2-z ; \mathrm{j}=1-x, y, 2-z ; \mathrm{k}=$ $x, 1-y, z ; 1=1 / 2-x, 3 / 2-y, 1-z ; \mathrm{m}=x+1 / 2,3 / 2-y, z ; \mathrm{n}=x-1 / 2,3 / 2-y, z$. (b) View of the triperiodic framework. (c) Nodal representation of the framework (uranium nodes, yellow; btc ${ }^{3-}$ nodes, dark blue; orientation slightly rotated with respect to that in part b).

While organic cations were used for the synthesis of complexes $\mathbf{1}-\mathbf{5}$, the other complexes, 6-11, include additional metal cations and are all heterometallic polymers since in no case is the additional metal-containing species separate, as a counterion, from the uranylbased coordination polymer. The two complexes $\left[\left(\mathrm{UO}_{2}\right)_{2}(\mathrm{btc})_{2} \mathrm{Ni}(\mathrm{cyclam})\right](6)$ and 
$\left[\left(\mathrm{UO}_{2}\right)_{2}(\mathrm{btc})_{2} \mathrm{Cu}\left(R, S-\mathrm{Me}_{6}\right.\right.$ cyclam $\left.)\right]$ (7) involve azamacrocyclic complexes of 3d-block metal cations. The unique uranyl cation and $\mathrm{btc}^{3-}$ ligand in complex 6 have the same connectivity as in $\mathbf{1}, \mathbf{3}$ and $\mathbf{4}$, and they form a uranyl-only monoperiodic coordination polymer parallel to [001] which is analogous to that found in $\mathbf{1}$. As shown in Figure 6, extension of the polymer occurs
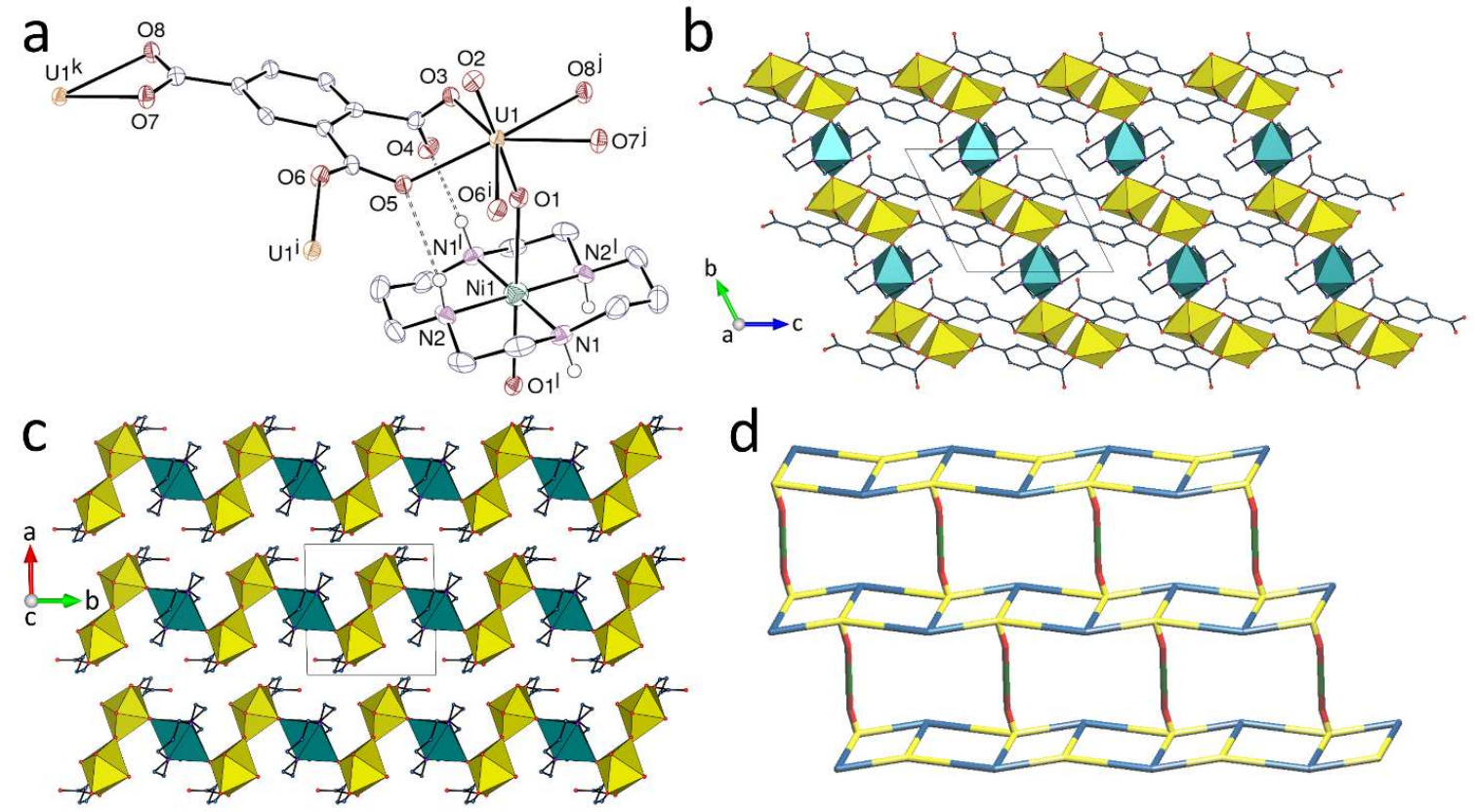

Figure 6. (a) View of compound 6. Displacement ellipsoids are drawn at the 50\% probability level. Carbon-bound hydrogen atoms are omitted and hydrogen bonds are shown as dashed lines. Symmetry codes: $\mathrm{i}=1-x, 1-y, 1-$ $z ; \mathrm{j}=x, y, z-1 ; \mathrm{k}=x, y, z+1 ; 1=1-x, 2-y, 1-z$. (b) View of the heterometallic diperiodic assembly with uranium coordination polyhedra yellow and those of nickel(II) green. (c) Packing with layers viewed edge-on. (d) Nodal representation of the diperiodic assembly (uranium nodes, yellow; nickel links, green; oxygen links, red; $\mathrm{btc}^{3-}$ nodes, dark blue; same orientation as in part b).

through bonding of one of the uranyl oxo groups to nickel(II), a mode of attachment which is rather common with the uranyl cation generally, but not found up to now in heterometallic compounds involving $\mathrm{Ni}^{\mathrm{II}}$ or $\mathrm{Cu}^{\mathrm{II}}$ azamacrocyclic complexes [U1=O1 1.772(4), Ni1-O1 2.516(4) $\AA, \mathrm{U} 1=\mathrm{O} 1-\mathrm{Ni} 1157.5(2)^{\circ}$ ]. Apart from being axially coordinated to two oxo groups, the nickel centre, located on an inversion centre, is bound to the four nitrogen atoms of cyclam and, as previously noted, hydrogen bonding of the amine groups to carboxylate oxygen atoms 
$\left[\mathrm{N} \cdots \mathrm{O} 2.878(7)\right.$ and $3.284(7) \AA, \mathrm{N}-\mathrm{H} \cdots \mathrm{O} 157$ and $\left.165^{\circ}\right]$ may exert a synergistic effect promoting $\mathrm{Ni}^{\mathrm{II}}$ axial bonding. In the present case, two hydrogen bonding rings containing both metal cations and with the graph set descriptors $R_{1}{ }^{1}(6)$ and $R_{1}{ }^{1}(8)$ are formed. The coordination polymer is diperiodic and parallel to (100), with uranium a $4-\mathrm{c}$ node, $\mathrm{btc}^{3-}$ a $3-\mathrm{c}$ node, and $\mathrm{Ni}^{\mathrm{II}}$ a simple link. The binodal net has the point symbol $\left\{4^{2} .6^{3} .8\right\}\left\{4^{2} .6\right\}$ and the topological type $\mathrm{V}_{2} \mathrm{O}_{5}$, previously found in other cases in which monoperiodic uranyl-only subunits are linked into a diperiodic net. ${ }^{19,41,42}$ The ribbon-like chain plane is much inclined with respect to the layer plane, which is sawtooth-shaped when viewed edge-on, and the packing has a KPI of 0.73 .

The uranyl/btc ${ }^{3-}$ connectivity in 7 is the same as in $\mathbf{1 , 3}, \mathbf{4}$ and $\mathbf{6}$, and these two components alone give the now usual monoperiodic coordination polymer, here parallel to [110] (Figure 7). In contrast to $\mathrm{Ni}^{\mathrm{II}}$ in $\mathbf{6}, \mathrm{Cu}^{\mathrm{II}}$, located on an inversion centre, is axially bound

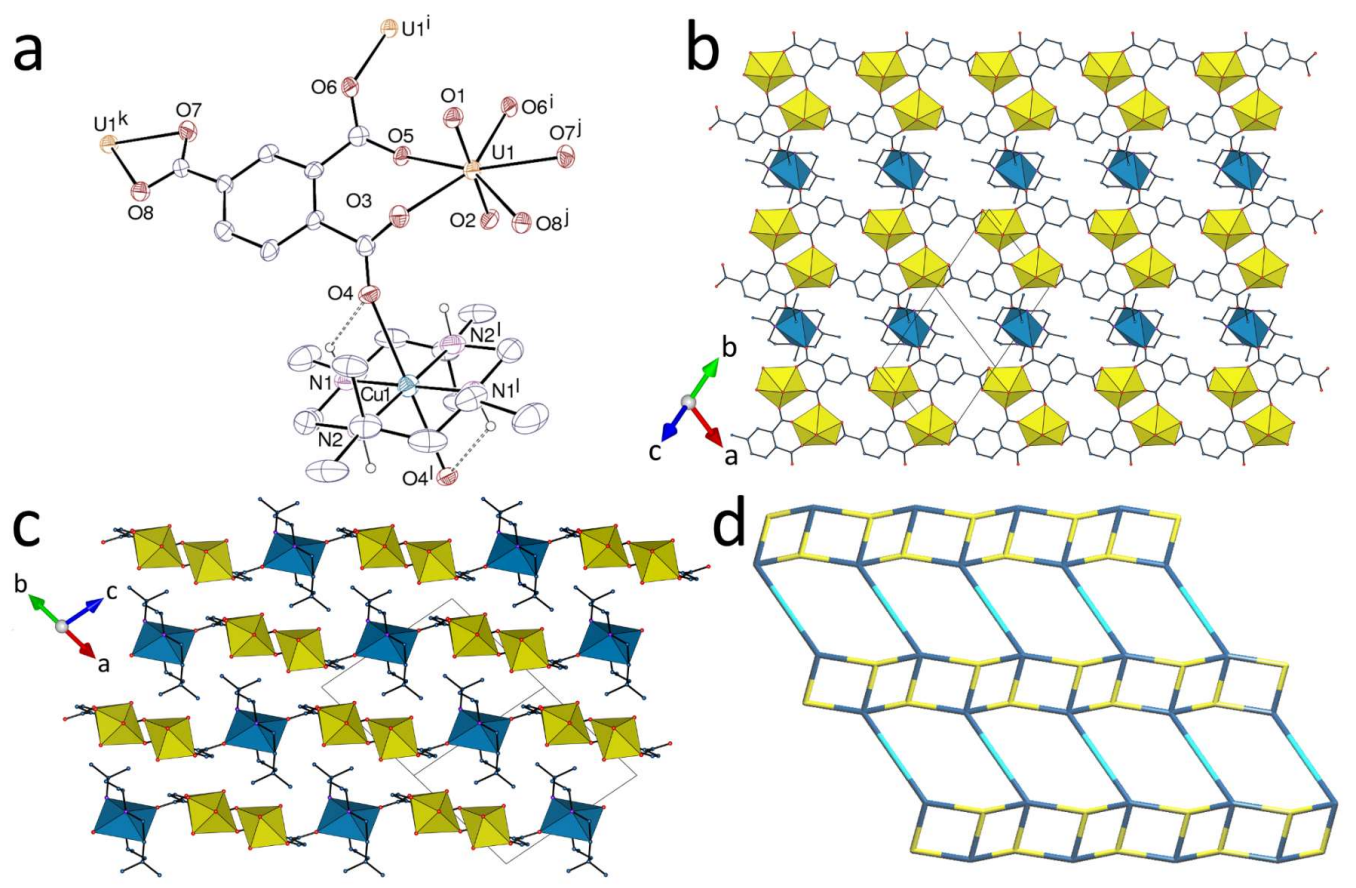

Figure 7. (a) View of compound 7. Displacement ellipsoids are drawn at the $30 \%$ probability level. Carbon-bound hydrogen atoms are omitted and hydrogen bonds are shown as dashed lines. Symmetry codes: $\mathrm{i}=1-x,-y, 2-z$; $\mathrm{j}=x-1, y-1, z ; \mathrm{k}=x+1, y+1, z ; 1=-x,-y, 1-z$. (b) View of the heterometallic diperiodic assembly with uranium coordination polyhedra yellow and those of copper(II) blue. (c) Packing with layers viewed edge-on. (d) Nodal representation of the diperiodic assembly (uranium nodes, yellow; copper links, light blue; btc ${ }^{3-}$ nodes, dark blue; same orientation as in part b). 
to the only carboxylate oxygen atom not coordinated to uranyl [Cu1-O4 2.551(6) $\AA$ ], so that a diperiodic assembly parallel to (1) in is formed, which has the same topology as that in $\mathbf{6}$. Here also, the amine groups are hydrogen bonded to carboxylate groups $[\mathrm{N} \cdots \mathrm{O} 2.731(10)$ and 2.963(11) $\AA, \mathrm{N}-\mathrm{H} \cdots \mathrm{O} 120$ and $115^{\circ}$ ]. Involvement of in-plane carboxylato instead of outwarddirected oxo groups in forming the links results in the layers being closer to planarity than in 6 . As a consequence, the aromatic rings are involved in an interlayer parallel-displaced $\pi$-stacking interaction [centroid $\cdots$ centroid distance $3.766(6) \AA$, dihedral angle $0^{\circ}$, slippage $1.57 \AA$ ]. The KPI of 0.72 is identical to that in 6.

The last four complexes involve simple additional metal cations, and two of them are heterometallic uranyl/silver(I) complexes, $\quad\left[\mathrm{UO}_{2} \mathrm{Ag}_{2}(\mathrm{Hbtc})_{2}\left(\mathrm{H}_{2} \mathrm{O}\right)_{2}\right] \quad$ (8) and $\left[\left(\mathrm{UO}_{2}\right)_{2} \mathrm{Ag}_{2}(\mathrm{btc})_{2}\left(\mathrm{CH}_{3} \mathrm{CN}\right)_{1.5}\left(\mathrm{H}_{2} \mathrm{O}\right)_{0.43}\right] \cdot 1.5 \mathrm{H}_{2} \mathrm{O}$ (9). Complex 9 has been synthesized with acetonitrile as organic cosolvent, while $\mathbf{8}$ was obtained under pure hydrothermal conditions, in the hope, which proved justified, of avoiding the extensive disorder present in 9 . The unique uranyl ion in $\mathbf{8}$ is chelated by two carboxylate groups in trans positions, and bound to two more carboxylate donors, while $\mathrm{Ag}^{\mathrm{I}}$ is bound to two carboxylate groups from different ligands [2.302(3) and 2.317(3) $\AA]$, one water molecule [2.505(3) $\AA]$, and the uranyl oxo group [2.599(3) Å] (Figure 8). Several examples of uranyl oxo bonding to $\mathrm{Ag}^{\mathrm{I}}$ are known, and the present $\mathrm{Ag} 1-$ O1 bond length is well within the usual wide range, $2.38-3.01 \AA . .^{41,43-48}$ It may be noted that the $\mathrm{U} 1=\mathrm{O} 1$ bond length, $1.783(3) \AA$, is the largest in the present series, possibly indicating a moderate lengthening due to silver coordination; the $\mathrm{U} 1=\mathrm{O} 1-\mathrm{Ag} 1$ angle is $134.78(14)^{\circ}$. The $\mathrm{Hbtc}^{2-}$ ligand is bound to four metal cations, i.e. one uranyl chelated by 1-carboxylate, one uranyl and one silver bridged by 2-carboxylate, and one silver bound in monodentate mode by the 4-carboxylic acid group. The latter forms a hydrogen bond with the coordinated water 


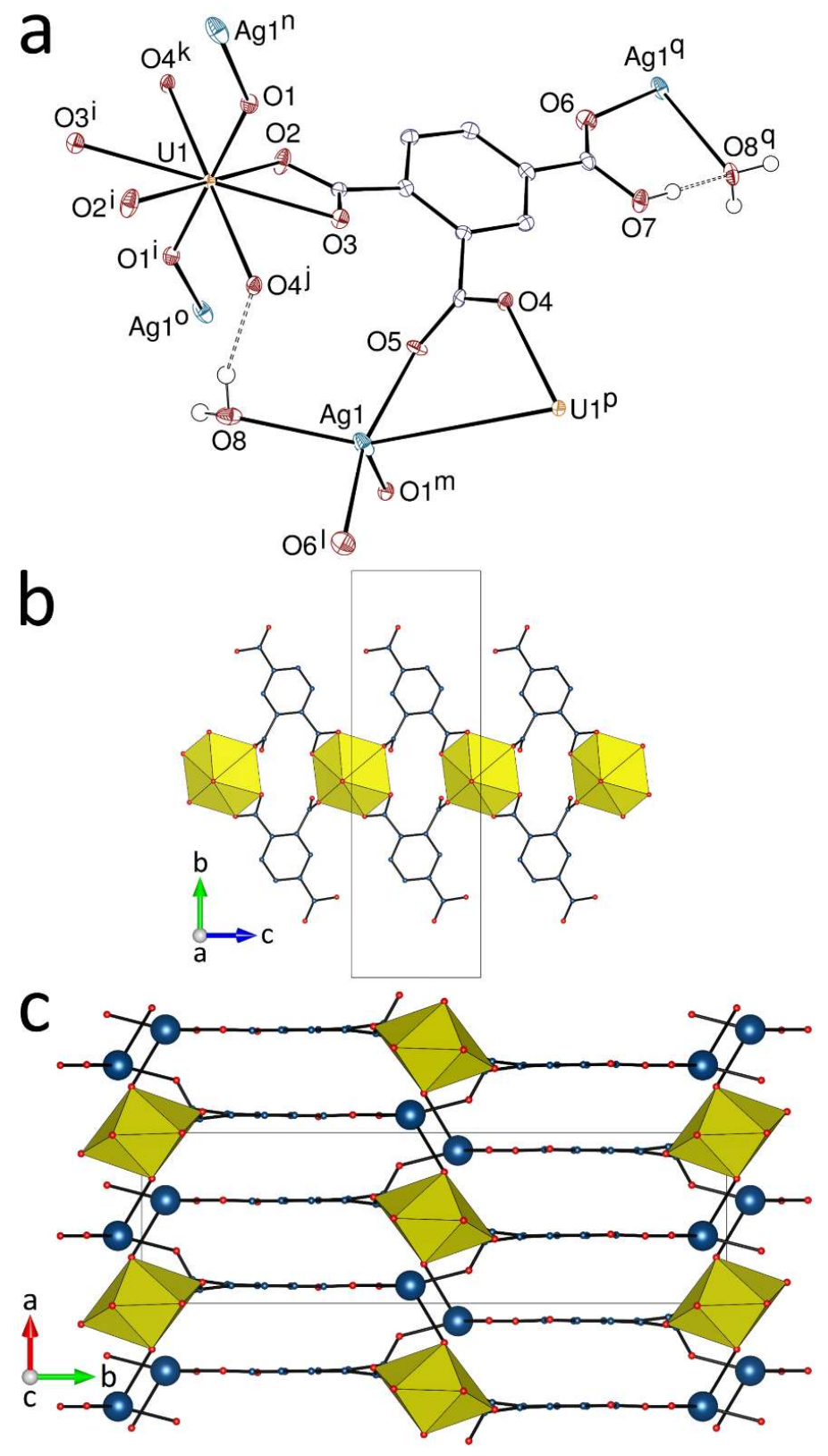

Figure 8. (a) View of compound 8. Displacement ellipsoids are drawn at the $50 \%$ probability level. Carbon-bound hydrogen atoms are omitted and hydrogen bonds are shown as dashed lines. Symmetry codes: $\mathrm{i}=1-x, 1-y, 2-$ $z ; \mathrm{j}=1-x, 1-y, 1-z ; \mathrm{k}=x, y, z+1 ; 1=1 / 2-x, y-1 / 2,1 / 2-z ; \mathrm{m}=x-1, y, z-1 ; \mathrm{n}=x+1, y, z+1 ; \mathrm{o}=-x, 1$ $-y, 1-z ; \mathrm{p}=x, y, z-1 ; \mathrm{q}=1 / 2-x, y+1 / 2,1 / 2-z$. (b) View of the uranyl-only monoperiodic coordination polymer. (c) View of the heterometallic triperiodic framework with uranium coordination polyhedra yellow and silver(I) ions shown as blue spheres.

molecule $\left[\mathrm{O} 7 \cdots \mathrm{O} 82.576(4) \AA, \mathrm{O} 7-\mathrm{H} \cdots \mathrm{O} 8179(7)^{\circ}\right]$, thus creating a $R_{1}{ }^{1}(6)$ ring, and the water molecule forms two hydrogen bonds with carboxylate groups [O‥O 2.667(4) and 2.714(4) $\AA$, 
$\mathrm{O}-\mathrm{H} \cdots \mathrm{O} 176(7)$ and $\left.162(6)^{\circ}\right]$. The polymeric assembly formed is a triperiodic framework and the point symbol for the $3,4,6-\mathrm{c}, 3$-nodal net is $\left\{4.6^{2} \cdot 7^{2} .8\right\}_{2}\left\{4^{2} \cdot 6^{4} \cdot 7 \cdot 8^{6} \cdot 9.10\right\}\left\{6.7^{2}\right\}_{2}$. However, a simpler representation is obtained when separating the uranyl-only polymer, which is monoperiodic and runs along [001]. The carboxylic groups project from the two edges of this ribbonlike chain, and the offset arrangement of the chains brings the silver(I) cations coordinated to one of them in the right position to bind to the oxo groups of another, thus ensuring triperiodic connectivity. Although the aromatic rings lie parallel to one another, the separation is large [centroid $\cdots$ centroid 4.664(2) $\AA$ ] and no significant $\pi$-stacking interaction is involved. Elongated channels run along [001], but there is no significant available space (KPI $0.76)$.

The structure of complex 9 is plagued by heavy disorder affecting one of the silver(I) cations (see Experimental Section). The two independent uranyl ions are in similar environments, being chelated by one carboxylate group and bound to three more carboxylate oxygen atoms from three different ligands (Figure 9). Ag1, in general position, is bound to one carboxylate group [2.205(8) $\AA]$, one uranyl oxo group [2.584(10) $\AA]$, and one acetonitrile molecule [2.171(11) $\AA$, while Ag2, located on an inversion centre, is only bound to two carboxylate groups $[2.184(8) \AA]$. All that can be said of the disordered and partially populated Ag3 site is that it is linked to an oxo group [2.526(9) $\AA$ ], and to disordered water and acetonitrile molecules. The two btc ${ }^{3-}$ ligands are similarly bound, with the 1-carboxylate bridging uranyl and silver cations, the 2-carboxylate chelating uranyl, and the 4-carboxylate bridging two uranyl cations. Uranyl cations and $\mathrm{btc}^{3-}$ ligands alone build a 4-c uninodal, diperiodic net parallel to (010), which has the point symbol $\left\{4^{4} \cdot 6^{2}\right\}$ and the very common sql topological type. These layers are assembled through oxo- and carboxylato-bound $\mathrm{Ag}^{\mathrm{I}}$ cations into a triperiodic framework which contains no significant free space (KPI not available due to the extended disorder). 


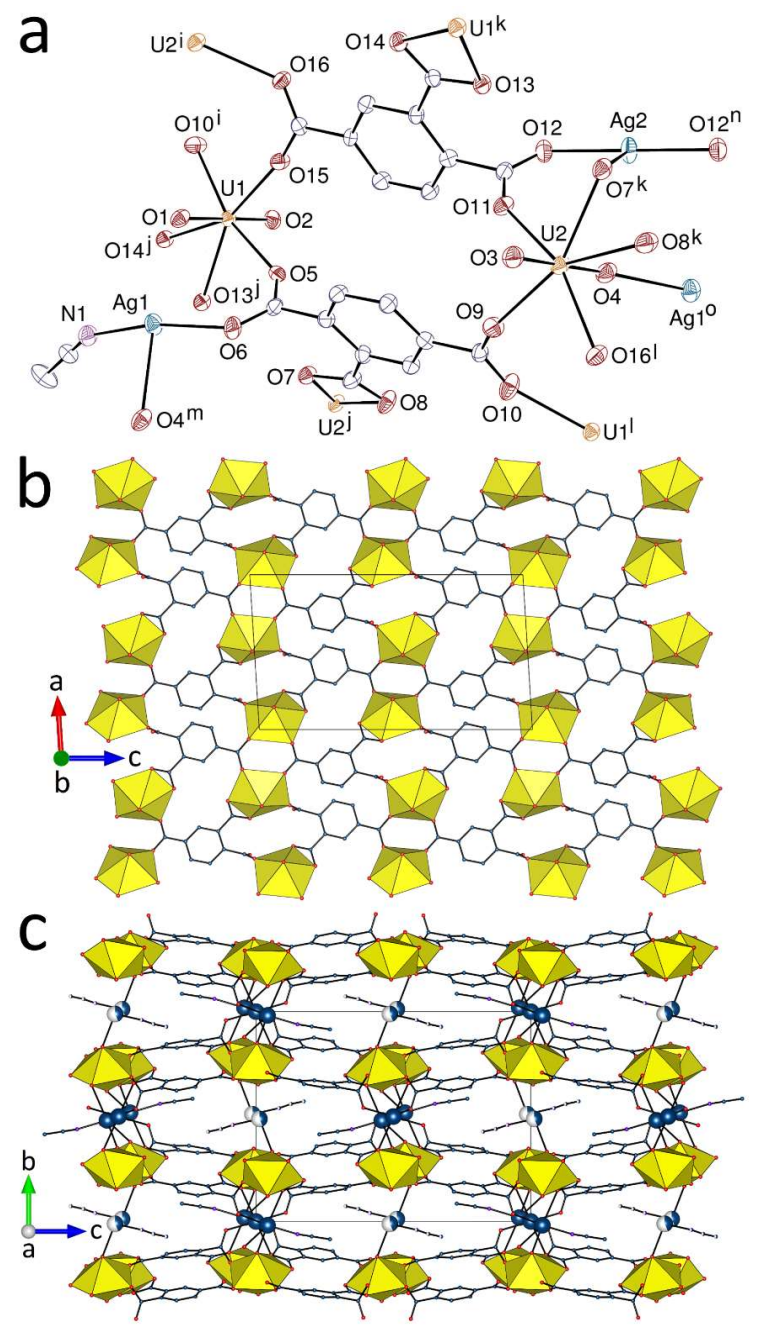

Figure 9. (a) View of compound 9. Displacement ellipsoids are drawn at the $30 \%$ probability level. The disordered $\mathrm{Ag}^{\mathrm{I}}$ cation, solvent molecules, and hydrogen atoms are omitted. Symmetry codes: $\mathrm{i}=x-1 / 2,1 / 2-y, z+1 / 2 ; \mathrm{j}=$ $x+1 / 2,1 / 2-y, z+1 / 2 ; \mathrm{k}=x-1 / 2,1 / 2-y, z-1 / 2 ; 1=x+1 / 2,1 / 2-y, z-1 / 2 ; \mathrm{m}=3 / 2-x, y+1 / 2,1 / 2-z ; \mathrm{n}=$ $1-x,-y,-z ; 0=3 / 2-x, y-1 / 2,1 / 2-z$. (b) View of the uranyl-only diperiodic assembly. (c) View of the heterometallic triperiodic framework with uranium coordination polyhedra yellow and silver(I) ions shown as blue spheres (parti-colored in the case of the disordered cations).

The last two complexes, $\left[\mathrm{UO}_{2} \mathrm{Rb}(\mathrm{btc})\left(\mathrm{H}_{2} \mathrm{O}\right)\right](\mathbf{1 0})$ and $\left[\mathrm{UO}_{2} \mathrm{Cs}(\mathrm{btc})\left(\mathrm{H}_{2} \mathrm{O}\right)\right](\mathbf{1 1})$, involve additional alkali metal cations and they are isomorphous. Unfortunately, no complex could be crystallized with $\mathrm{Li}^{+}, \mathrm{Na}^{+}$or $\mathrm{K}^{+}$for comparison, this being an indication that the structures in these cases are probably different. Among all uranyl complexes with $b_{t c}^{3-}, \mathbf{1 0}$ and $\mathbf{1 1}$ are the 
only examples in which the ligand is tris- $\kappa^{2} O, O^{\prime}$-chelating toward uranyl, as shown in Figure 10 for complex $\mathbf{1 0}$. The 1-carboxylate group is also bridging two $\mathrm{Rb}^{+} / \mathrm{Cs}^{+}$cations, while the 2-

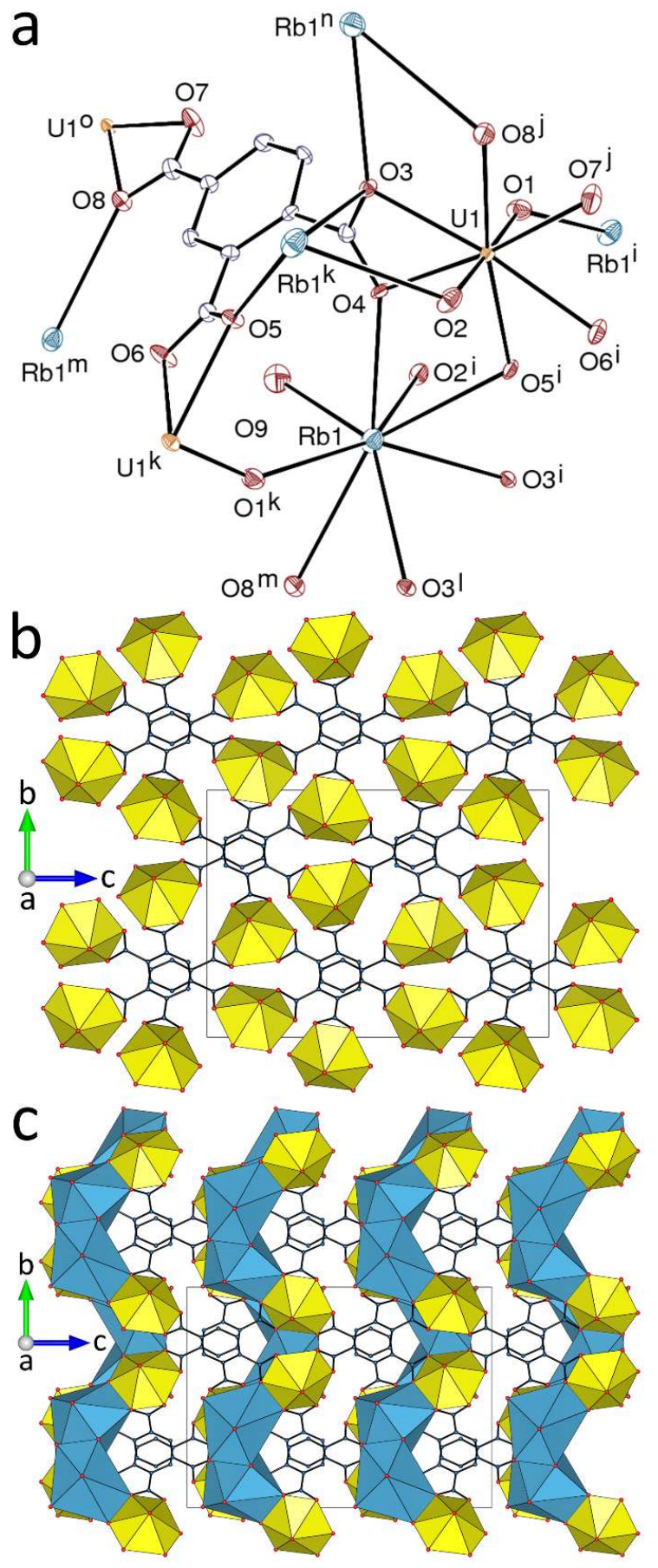

Figure 10. (a) View of compound 10 (isomorphous with 11). Displacement ellipsoids are drawn at the $50 \%$ probability level and hydrogen atoms are omitted. Symmetry codes: $\mathrm{i}=x+1 / 2,1-y, 1 / 2-z ; \mathrm{j}=x, 1 / 2-y, z-$ $1 / 2 ; \mathrm{k}=x-1 / 2,1-y, 1 / 2-z ; 1=1-x, y+1 / 2,1 / 2-z ; \mathrm{m}=1-x, 1-y, 1-z ; \mathrm{n}=1-x, y-1 / 2,1 / 2-z ; \mathrm{o}=x, 1 / 2$ $-y, z+1 / 2$. (b) View of the uranyl-only triperiodic interpenetrated assembly. (c) View of the heterometallic triperiodic framework with uranium coordination polyhedra yellow and those of rubidium blue. 


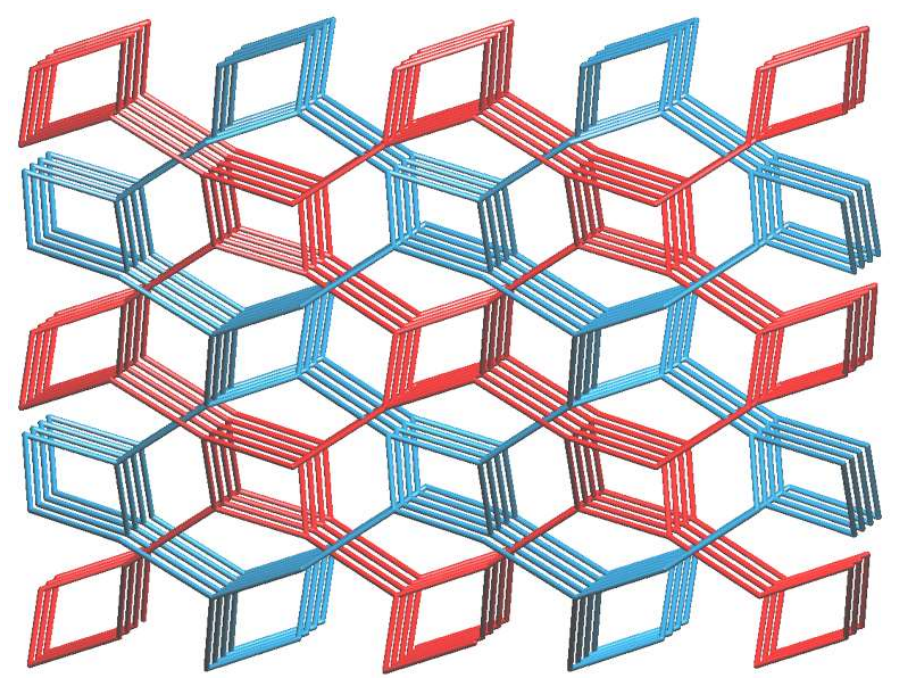

Figure 11. Nodal representation of the 2-fold interpenetrated utp triperiodic uranyl-only frameworks in $\mathbf{1 0}$ and $\mathbf{1 1}$ ([010] vertical, [001] horizontal).

and 4-carboxylates are bound to only one additional cation, the respective coordination modes being $\mu_{3}-\kappa^{2} O, O^{\prime}: \kappa^{1} O: \kappa^{1} O^{\prime}$ and $\mu_{2}-\kappa^{2} O, O^{\prime}: \kappa^{1} O$. The unique $\mathrm{Rb}^{+} / \mathrm{Cs}^{+}$cation is bound to five carboxylate oxygen atoms pertaining to five ligands [2.985(4)-3.282(4) $\AA$ for Rb, 3.090(3)3.298(3) $\AA$ for Cs], two uranyl oxo groups [2.946(4) and 3.039(4) $\AA$ for Rb, 3.089(3) and 3.187(3) $\AA$ for $\mathrm{Cs}]$, and one water molecule [2.880(5) $\AA$ for Rb, 3.001(4) $\AA$ for Cs]. Many examples are known of uranyl oxo bonding to alkali metal atoms and, in the cases of $\mathrm{Rb}^{+}$and $\mathrm{Cs}^{+}$, the bond lengths are in the ranges of 2.81-3.36 and 3.09-3.83 $\AA$, respectively. ${ }^{49-59} \mathrm{The}$ alkali metal ion is octa-coordinated, with an environment of irregular geometry. Overall, a very intricate 5,6,7-c, 3-nodal triperiodic framework is formed in which corrugated sheets of cations parallel to (001) are separated by layers of ligands. However, if the alkali metal ions are disregarded, uranyl and btc $^{3-}$ ligands alone form a 3-c, uninodal triperiodic framework which has the point symbol $\left\{10^{3}\right\}$ and the topological type utp. Interestingly, this framework displays class IIa, 2-fold interpenetration with inversion as full interpenetration symmetry element ${ }^{60}$ (Figure 11), and it is thus one novel example of an entangled (interpenetrated or polycatenated) 
uranyl-based coordination polymer, several such compounds having been reported recently. ${ }^{2,19,61-67}$ More generally, the utp topology accounts for about $1.2 \%$ of interpenetrating triperiodic structures, according to a survey of the cases published before $2009,{ }^{68}$ and it is much less frequent than the dia and pcu topologies; in contrast, class II interpenetration (i.e. in which the different nets are related by space group symmetry elements, not translations) is common, accounting for about one third of the cases. ${ }^{60}$ It is also notable that the alkali metal cations and $\mathrm{btc}^{3-}$ ligands alone form themselves a 4-c, uninodal triperiodic framework with the point symbol $\left\{4^{2} \cdot 6^{2} \cdot 8^{2}\right\}$ and the $\mathbf{d f t}$ topological type. As a consequence of entanglement, the structures of $\mathbf{1 0}$ and 11 do not display any significant free space (KPI 0.78/0.79). One parallel-displaced $\pi$ -

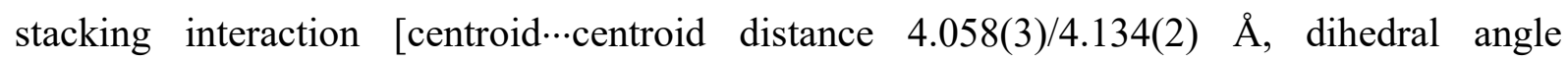
$\left.17.9(3) / 22.34(18)^{\circ}\right]$ possibly plays a role in the assembly.

The 11 complexes reported here allow a discussion of the effect of the particular, asymmetric isomeric form of the btc ${ }^{3-}$ ligand used on the connectivity and periodicity observed. The coordination modes in complexes 1-11 are shown in Scheme 1, in which the ligands are represented as planar for clarity, and Table 2 gives, for each complex, the coordination mode of each carboxylic/ate group and the dihedral angles formed by the three $\mathrm{COO}$ groups with the aromatic ring, as well as the dihedral angle between the 1- and 2-carboxylate groups. It appears that the 4-carboxylate, which is not affected by steric hindrance with an adjacent group, is never much rotated out of the ring plane, the dihedral angles being in the 1.6(5)-13.2(3) ${ }^{\circ}$ range, except for one larger value, $20.1(5)^{\circ}$ in one ligand in 9. It is notable that the 4-carboxylate group is most often $\kappa^{2} O, O^{\prime}$-chelating, this being the case in 8 out of 11 complexes (with extra bridging in two cases). In contrast, the 1- and 2-carboxylate groups display the effect of steric hindrance, with a dihedral angle between these two groups in the range of 42.6(3)-89.6(8) ${ }^{\circ}$. Except in complex 8 and in one of the two ligands in $\mathbf{2}$, the 1-carboxylate is more tilted than the 2carboxylate with respect to the aromatic ring. In the five complexes in which one uranyl cation 


\section{Scheme 1. Coordination Modes of the $\mathrm{btc}^{3-} / \mathrm{Hbtc}^{2-}$ Ligands in Complexes 1-11.}<smiles></smiles><smiles></smiles><smiles></smiles><smiles></smiles><smiles></smiles><smiles></smiles>

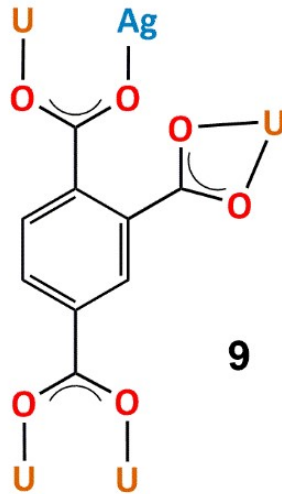<smiles>[M]OC(=O)c1ccc(C(O[M])O[M])c(C2O[SiH](O[M])O2)c1</smiles>

Table 2. Coordination Mode and Geometry of $\mathrm{btc}^{3-} / \mathrm{Hbtc}^{2-}$ in Complexes 1-11

\begin{tabular}{|c|c|c|c|c|c|c|c|}
\hline & $\begin{array}{c}\text { coordination mode of } \\
\text { 1-carboxylate }\end{array}$ & $\begin{array}{l}\text { coordination mode of } \\
\text { 2-carboxylate }\end{array}$ & $\begin{array}{l}\text { coordination mode of } \\
\text { 4-carboxylate }\end{array}$ & $\begin{array}{l}\text { dihedral angle }\left(^{\circ}\right) \\
\text { 1-carboxylate/ring }\end{array}$ & $\begin{array}{l}\text { dihedral angle }\left(^{\circ}\right) \\
\text { 2-carboxylate/ring }\end{array}$ & $\begin{array}{l}\text { dihedral angle }\left({ }^{\circ}\right) \\
\text { 1-/2-carboxylate }\end{array}$ & $\begin{array}{l}\text { dihedral angle }\left(^{\circ}\right) \\
\text { 4-carboxylate/ring }\end{array}$ \\
\hline 1 & $\kappa^{1} O$ & $\mu_{2}-\kappa^{1} O: \kappa^{1} O^{\prime}$ & $\kappa^{2} O, O^{\prime}$ & $44.18(15)$ & $28.5(2)$ & 47.1(3) & $11.13(17)$ \\
\hline 2 & n.c. ${ }^{a}$ or $\kappa^{2} O, O^{\prime}$ & $\kappa^{2} O, O^{\prime}$ or n.c. & $\kappa^{2} O, O^{\prime}$ & $86.9(6) / 1.6(21)$ & $4.1(7) / 75.4(8)$ & $89.6(8) / 77.0(11)$ & $3.6(11) / 1.6(21)$ \\
\hline 3 & $\kappa^{1} O$ & $\mu_{2}-\kappa^{1} O: \kappa^{1} O^{\prime}$ & $\kappa^{2} O, O^{\prime}$ & $43.5(2)$ & $37.14(11)$ & $42.6(3)$ & $13.2(3)$ \\
\hline 4 & $\kappa^{1} O$ & $\mu_{2}-\kappa^{1} O: \kappa^{1} O^{\prime}$ & $\kappa^{2} O, O^{\prime}$ & $50.12(16) / 52.6(2)$ & $5.9(2) / 7.6(4)$ & $54.0(2) / 54.9(3)$ & $7.3(3) / 10.2(4)$ \\
\hline 5 & $\mu_{2}-\kappa^{1} O: \kappa^{1} O^{\prime}$ & $\kappa^{2} O, O^{\prime}$ & $\mu_{2}-\kappa^{1} O: \kappa^{1} O^{\prime}$ & $85.8(3)$ & $2.4(6)$ & $87.2(7)$ & $9.2(3)$ \\
\hline 6 & $\kappa^{1} O$ & $\mu_{2}-\kappa^{1} O: \kappa^{1} O^{\prime}$ & $\kappa^{2} O, O^{\prime}$ & $63.0(5)$ & $8.8(9)$ & $64.2(8)$ & $6.5(11)$ \\
\hline 7 & $\mu_{2}-\kappa^{1} O: \kappa^{1} O^{\prime}$ & $\mu_{2}-\kappa^{1} O: \kappa^{1} O^{\prime}$ & $\kappa^{2} O, O^{\prime}$ & $37.4(7)$ & $34.4(10)$ & $43.4(13)$ & $12.9(10)$ \\
\hline 8 & $\kappa^{2} O, O^{\prime}$ & 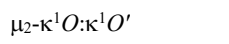 & $\kappa^{1} O$ (protonated) & $21.3(2)$ & $64.75(16)$ & $68.2(3)$ & $2.5(3)$ \\
\hline 9 & $\mu_{2}-\kappa^{1} O: \kappa^{1} O^{\prime}$ & $\kappa^{2} O, O^{\prime}$ & $\mu_{2}-\kappa^{1} O: \kappa^{1} O^{\prime}$ & $79.4(5) / 88.5(5)$ & $11.3(11) / 9.3(6)$ & $71.6(11) / 80.5(9)$ & $3.3(8) / 20.1(5)$ \\
\hline 10 & $\mu_{3}-\kappa^{2} O, O^{\prime}: \kappa^{1} O: \kappa^{1} O^{\prime}$ & $\mu_{2}-\kappa^{2} O, O^{\prime}: \kappa^{1} O$ & $\mu_{2}-\kappa^{2} O, O^{\prime}: \kappa^{1} O$ & $63.5(2)$ & $15.9(8)$ & $66.0(5)$ & $2.4(6)$ \\
\hline 11 & $\mu_{3}-\kappa^{2} O, O^{\prime}: \kappa^{1} O: \kappa^{1} O^{\prime}$ & $\mu_{2}-\kappa^{2} O, O^{\prime}: \kappa^{1} O$ & $\mu_{2}-\kappa^{2} O, O^{\prime}: \kappa^{1} O$ & $65.86(17)$ & $16.6(6)$ & $67.6(3)$ & $1.6(5)$ \\
\hline
\end{tabular}

is chelated by these two groups $(\mathbf{1}, \mathbf{3}, \mathbf{4}, \mathbf{6}$ and $\mathbf{7})$, the 1-COO/2-COO angle is in the range of $42.6(3)-64.2(8)^{\circ}$, with either both groups rotated from the aromatic ring by $28.5(2)-44.18(15)^{\circ}$ (1, 3 and 7), or the 2-carboxylate group nearly coplanar with the ring (4 and 6). All these 
complexes crystallize as mono- or diperiodic polymers only. The two ligands in complex 2 have the disordered uncomplexed carboxylic group in different positions, but in both cases the uncomplexed carboxylate is nearly orthogonal to the ring while the complexed carboxylate groups are nearly coplanar with it, which results in the formation of a nearly planar monoperiodic polymer. In the two cases in which the 1-carboxylate is nearly orthogonal to the ring while 2-carboxylate is close to it and both are complexed (5 and $\mathbf{9})$, these being moreover two cases in which as many as five metal cations are bound to each ligand, a triperiodic framework is formed, due to the out-of-plane rotation of the 1-carboxylate group, as visible in Figures 5 and 9, an observation in keeping with former findings. ${ }^{3,4}$ However, in the other triperiodic structures in the present series $(\mathbf{8}, \mathbf{1 0}$ and 11), there is no carboxylate group orthogonal to the ring, one of them (2-COO in 8, 1-COO in $\mathbf{1 0}$ and 11) making a dihedral angle of $63.5(2)-65.86(17)^{\circ}$ with the ring, and the other being much closer to the plane, with an angle of $15.9(8)-21.3(2)^{\circ}$. In these cases, the presence of additional metal cations, some of them oxocoordinated to uranyl, probably plays an essential role, and it is notable that the highest number of 7 cations bound to one btc ${ }^{3-}$ ligand is attained in complexes $\mathbf{1 0}$ and 11. Comparison with the known structures involving the other isomers of benzenetricarboxylate enables definition of the specificities of each. The three carboxylate groups in the two uranyl ion complexes with 1,3,5$\mathrm{Hbtc}^{2-}$ are nearly coplanar with the aromatic ring (dihedral angles of $1-14^{\circ}$ ) and as a result the assemblies formed are monoperiodic. ${ }^{5,7}$ In contrast, in the uranyl ion complex with 1,2,3-btc ${ }^{3-}$ (as well as in most complexes involving other metal cations reported in the CSD), the central carboxylate group is nearly orthogonal to the aromatic ring (dihedral angle $79^{\circ}$ ) while the lateral groups are nearly coplanar with it $\left(2\right.$ and $\left.11^{\circ}\right)$, which ensures formation of a triperiodic framework..$^{3,4}$ The present 1,2,4-btc ${ }^{3-}$ ligand presents an interesting intermediate case, in which the geometry is more variable than in the other two isomers, and not quasi-planar as that of the 
$1,3,5$ form, thus allowing modulation of the periodicity through variations in the counterions or additional metal cations.

In comparing in deeper detail the present results with literature data for uranyl ion complexes of all three isomeric benzene tricarboxylates, some perhaps unexpected points of communality as well as points of disparity are apparent. The literature provides structures for complexes formulated as $\left[\left(\mathrm{UO}_{2}\right)_{3}(1,2,3-b t c)_{2}\left(\mathrm{H}_{2} \mathrm{O}\right)_{4}\right]\left(\mathbf{1 2}^{3}\right.$ and $\left.\mathbf{1 3}^{4}\right),\left[\mathrm{H}_{2} \mathrm{NMe}_{2}\right]\left[\left(\mathrm{UO}_{2}\right)_{2} \mathrm{O}(1,2,4-\right.$ btc) $] \cdot \mathrm{H}_{2} \mathrm{O} \quad\left(\mathbf{1 4}^{3}\right), \quad\left[\mathrm{H}_{3} \mathrm{O}\right]\left[\left(\mathrm{UO}_{2}\right)_{6} \mathrm{O}(\mathrm{OH})(1,2,4-\mathrm{btc})_{2}(1,2,4-\mathrm{Hbtc})_{2}\left(\mathrm{H}_{2} \mathrm{O}\right)_{2}\right] \cdot 6 \mathrm{H}_{2} \mathrm{O}$ $[\mathrm{DMPD}]\left[\mathrm{H}_{3} \mathrm{O}\right]\left[\mathrm{H}_{2} \mathrm{NMe}_{2}\right]_{2}\left[\left(\mathrm{UO}_{2}\right)_{5} \mathrm{O}_{3}(\mathrm{OH})(\mathrm{HCOO})(1,2,4-\text { btc })_{2}\right] \cdot \mathrm{DMF} \cdot \mathrm{H}_{2} \mathrm{O}$

$\left[\mathrm{NEt}_{4}\right]_{2}\left[\left(\mathrm{UO}_{2}\right)_{2}(1,2,4-\mathrm{btc})_{2}\left(\mathrm{H}_{2} \mathrm{O}\right)\right] \cdot 5 \mathrm{H}_{2} \mathrm{O} \quad\left(\mathbf{1 7}^{14}\right), \quad\left[\mathrm{UO}_{2}\left(\mathrm{H}_{2} \mathrm{O}\right)_{2}(1,2,4-\mathrm{Hbtc})\right]_{2} \cdot 2 \mathrm{H}_{2} \mathrm{O} \quad\left(\mathbf{1 8}^{4}\right)$, $\left[\mathrm{UO}_{2}(1,3,5-\mathrm{Hbtc})\left(\mathrm{H}_{2} \mathrm{O}\right)\right] \cdot \mathrm{H}_{2} \mathrm{O}\left(\mathbf{1 9}^{5}\right)$ and $\left[\mathrm{UO}_{2}(1,3,5-\mathrm{Hbtc})\left(\mathrm{H}_{2} \mathrm{O}\right)\right]\left(\mathbf{2 0}^{7}\right)$. In each of these structures, as well as in each of those presently reported, at least one and frequently two of the carboxylate groups lie close to coplanarity with the benzene ring (Tables 1 and S1, Figures S1S4, Supporting Information), indicating that conjugation of the carboxylate units with the ring must be a significant influence, although even in the case of the $1,3,5-\mathrm{Hbtc}^{2-}$ ligand, ${ }^{5,7}$ where direct repulsive interactions between the carboxylates must be minimal, there is no true coplanarity. The extreme deviations from coplanarity are seen where carboxylate units are adjacent, as in all 1,2,3- and 1,2,4-btc complexes (and as long known for the same entity in phthalate complexes ${ }^{12,69}$ ) and on the basis of the previously reported structures $\mathbf{1 2}-\mathbf{1 8}$ alone, this does appear to be associated with the preferential adoption of triperiodic structures, complex 18, where a simple dimer is present, providing the only exception. In the present series, however, triperiodic structures are less frequent and only 5, 10 and 11 provide examples where the uranyl-carboxylate component itself is triperiodic, complexes 8 and 9 being triperiodic only because of $\mathrm{Ag}^{\mathrm{I}}$ bridging of simpler uranyl-carboxylate polymers. Similarly, the diperiodic nature of complexes 6 and 7 is a result of heterometal bridging of monoperiodic uranylcarboxylate polymers. It is notable that in all the complexes 1-9 there are units within the 
structures that can be regarded as essentially planar uranyl-carboxylate entities (i.e. where the equatorial plane of the uranyl centres is close to coplanar with the benzene rings; Figure S1), further exemplifying the well-known tendency of uranyl carboxylates to adopt sheet-like structures. ${ }^{1}$ There is also a remarkable similarity between the monoperiodic uranyl polymers found in complexes $\mathbf{1 , 4 , 6}$ and 7 and those in both the 1,3,5-Hbtc ${ }^{2-}$ complexes $\mathbf{1 9}$ and $\mathbf{2 0}$, where planar arrays might have been anticipated (Figure S2). It is even possible to discern puckered sheet-like structures within the truly triperiodic uranyl species $\mathbf{1 0}$ and $\mathbf{1 1}$, although they cannot be described as planar in regard to the benzene ring orientations. A particular feature in common to the monoperiodic arrays in $\mathbf{1 , 4 , 6 , 7 , 1 9}$ and $\mathbf{2 0}$ as well as the diperiodic arrays in complexes 3 and $\mathbf{9}$, in addition to their near-planar nature, is the presence of binuclear units where carboxylate groups in a $\mu_{2}-\kappa^{1} O ; \kappa^{1} O^{\prime}$ mode bridge uranyl centres to form 8 -membered dimetallacycles. These all have essentially the form of the simple dimer found within the structure of 18 (Figure S3), incidentally indicating that conversion of the ligand from its dianionic to its trianionic form cannot alone produce major structural changes. There is clearly some flexibility associated with the 8-membered ring, since its conformation in complexes $\mathbf{1}$, 3, 6, 7 and 18 can be described as a chair, while in complexes 4 and 9 it has a boat form and in complexes 19 and 20 (perhaps different because no 7-membered chelate adjacent to the metallacycle can form, though no such chelate occurs in 9, either), it adopts a nearly flat form in the former and half-chair and twist-boat form in the latter. This may signify a mechanism for accommodation to some extent of changes associated with ligand deprotonation.

In the present study, no hydrolytic oligomerization as in the known species 14, 15 and 16 was observed but uranyl centres in both pentagonal- and hexagonal-bipyramidal coordination, along with one instance of square-bipyramidal (octahedral) coordination, were a source of some variety in the geometry of the structures. In complexes $\mathbf{1 , 3 , 4 , 6 , 7}$ and $\mathbf{9}$, pentagonal-bipyramidal centres only are present, while complex 5 has pentagonal- and square- 
bipyramidal centres and complexes 2, 8, 10 and $\mathbf{1 1}$ have only hexagonal-bipyramidal centres. In 1, 3-7 and 9, pentagonal-bipyramidal coordination is associated with 8-membered diuranacycle formation and as well with adjacent 7-membered, phthalate-like chelate ring formation except in the cases of $\mathbf{5}$ and $\mathbf{9}$. In $\mathbf{5}$, both the unique hydrogen bonding interactions involving the quinuclidinium cation, water molecule and coordinated carboxylate oxygen atoms, as well as the bridging by $\mathrm{U} 1$ must perturb this coupling, while in 9 this perturbation must be attributed to the coordination requirements of $\mathrm{Ag}^{\mathrm{I}}$. Hexagonal-bipyramidal coordination in 2, $\mathbf{1 0}$ and $\mathbf{1 1}$ involves commonly encountered $\mathrm{UO}_{2}\left(\kappa^{2} O, O^{\prime} \text {-carboxylate }\right)_{3}$ centres but in 8 has a trans $-\mathrm{UO}_{2}\left(\mathrm{H}_{2} \mathrm{O}\right)_{2}\left(\kappa^{2} O, O^{\prime} \text {-carboxylate }\right)_{2}$ form, with influences including ligand protonation levels, hydrogen bonding $(\mathrm{CH} \cdots \mathrm{O}$ and $\mathrm{OH} \cdots \mathrm{O})$ and metal ion coordination presumably all giving rise to the differences. In $\mathbf{1 0}$ and $\mathbf{1 1}$, the ability of a $\mathrm{UO}_{2}\left(\kappa^{2} O, O^{\prime}-\right.$ carboxylate) $)_{3}$ unit to act as a chelate ligand for alkali metal ions, seen, for example, in the simple complex $\mathrm{Na}\left[\mathrm{UO}_{2}\left(\mathrm{O}_{2} \mathrm{CCH}_{3}\right)_{3}\right]{ }^{70}$ is operative although augmented by further chelation involving uranyl oxo groups. Although there is no structural information in the case of 1,3,5-btc, the use of alkali metal countercations for "[ $\left.\mathrm{UO}_{2}(1,3,5-\mathrm{btc})\right]^{-"}$ " would seem to be a likely way of generating a triperiodic species.

Luminescence properties. Emission spectra under excitation at $420 \mathrm{~nm}$ were recorded for complexes $\mathbf{1 - 5}, \mathbf{7}, \mathbf{1 0}$ and $\mathbf{1 1}$ in the solid state, but the copper(II) complex $\mathbf{7}$ is nonluminescent, probably due either to preferential absorption of the $420 \mathrm{~nm}$ radiation by the transition metal centre, or to the latter allowing energy transfer and nonradiative relaxation. ${ }^{71-}$ ${ }^{76}$ The spectra of the other complexes were not measured since a sufficient quantity of pure sample could not be isolated. The spectra of the luminescent complexes, shown in Figure 12, 


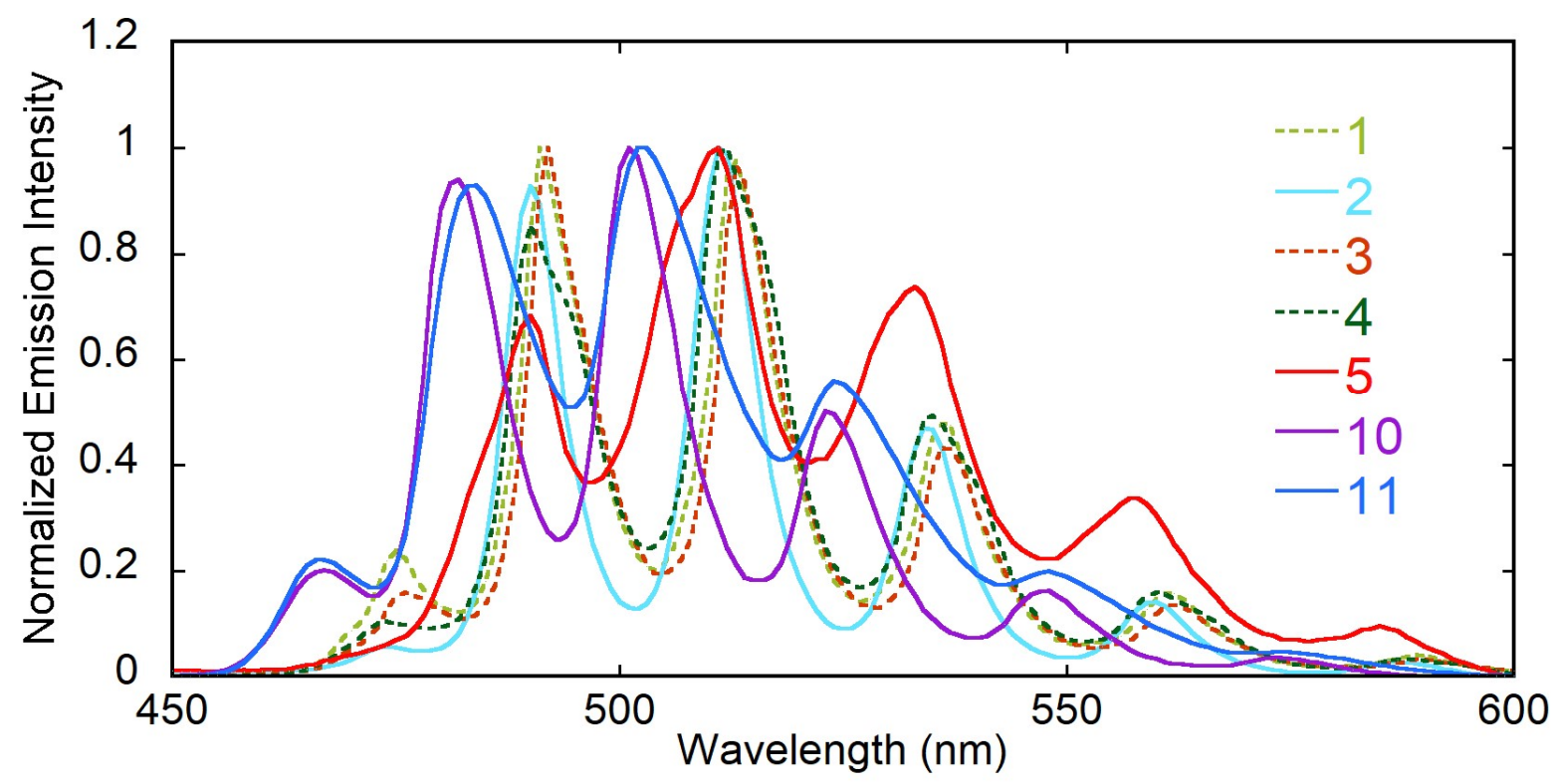

Figure 12. Emission spectra of compounds $\mathbf{1 - 5 , 1 0}$ and $\mathbf{1 1}$ in the solid state at room temperature, under excitation at a wavelength of $420 \mathrm{~nm}$.

display the usual fine structure associated with the vibronic progression corresponding to the $S_{11} \rightarrow S_{00}$ and $S_{10} \rightarrow S_{0 v}(v=0-4)$ electronic transitions. ${ }^{77}$ Complexes $\mathbf{1 0}$ and 11, with the uranyl cation in an $\mathrm{O}_{6}$ equatorial environment (tris-chelation) have maxima positions for the main four peaks at $482 / 484,501 / 503,523 / 524$ and $548 \mathrm{~nm}$, these values being typical of such environments. ${ }^{61,78}$ The spectrum of complex 2, also with an $\mathrm{O}_{6}$ environment, is however redshifted by about $8 \mathrm{~nm}$. The spectra of complexes 1,3 and 4, all with an $\mathrm{O}_{5}$ equatorial environment, are shown as dashed lines and have maxima positions at 490-492, 512-513, 535536 and $560-562 \mathrm{~nm}$, these values being at the lower end of the range corresponding to this environment. ${ }^{61,78}$ Finally, the spectrum of complex $\mathbf{5}$, which contains a mixture of $\mathrm{O}_{4}$ and $\mathrm{O}_{5}$ environments, clearly shows the presence of shoulders in the main peaks which probably arises from the superposition of two slightly different emission features; the main maxima, at 490, 511,533 and $557 \mathrm{~nm}$, are close to those for complexes with $\mathrm{O}_{5}$ environments.

That well-resolved vibronic progressions considered typical of uranyl ion are seen in all the presently recorded emission spectra offers support for the conclusion ${ }^{14}$ that the poorly- 
resolved, broadened emission seen in $\mathbf{1 6}$ (but not in 17) and similar to that in both $\mathbf{1 4}$ and $\mathbf{1 5}$, as well as, saliently, in the spectra of the phthalate complexes $\mathrm{A}\left[\left(\mathrm{UO}_{2}\right)_{3} \mathrm{O}(\mathrm{OH})\left(\mathrm{H}_{2} \mathrm{O}\right)(\text { phthalate })_{2}\right]\left(\mathrm{A}=\mathrm{K}, \mathrm{NH}_{4}\right)^{69}$ must reflect uranyl-uranyl interactions within the hydroxo/oxo bridged clusters found in those structures, interactions which are presumably stronger than those in the dimeric units seen here. Broad, "atypical" emissions, sometimes ascribed to the presence of organic fluorophores, ${ }^{3,79}$ have long been known in uranyl ion complexes, however, and it would seem that a variety of explanations may be required. We have recently discussed other instances of broad emission from uranyl complexes and have rationalised some in terms of aromatic $\cdots$ aromatic interactions within the structures, ${ }^{80}$ although clearly the same explanation could not be applied to explain broad emission in systems such as adamantanedicarboxylate complexes where the ligand is not aromatic. ${ }^{81}$ Other recent work has provided description of systems where broad emissions have long (millisecond) decay lifetimes and thus are clearly uranium- and not ligand-based. ${ }^{82}$ In regard to potential applications of uranyl ion complexes as photo-oxidants, it is of course essential that excited states of the uranyl unit be accessible.

Photoluminescence quantum yields (PLQYs) increase from the smallest value found for $5(1.3 \%)$, to those for $4(6.6 \%), 11(7.8 \%), 3(9.0 \%), 10(12.9 \%), 2(17.4 \%)$, and $1(35.0 \%)$. The difference between the values for $\mathbf{1}$ and $\mathbf{2}$ may be related, at least in part, to the presence of water solvent in the latter resulting in partial quenching. The value for $\mathbf{1}$ exceeds that measured under the same conditions for uranyl nitrate hexahydrate (24\%), and it is among the largest found in a uranyl carboxylate complex, other large values having been found in some complexes with $(1 R, 3 S)-(+)$-camphorate $(23 \%),{ }^{83}$ dipicolinate $(42 \%),{ }^{83}$ succinate $(49 \%),{ }^{84}$ and 1,3,5- benzenetricarboxylate (58\%). ${ }^{7}$ Such large PLQY values are a requisite in the prospect of using uranyl ion complexes containing isolated cavities as photoactive devices, ${ }^{85}$ but, as seen in the present examples, these may vary widely for solids of similar composition and structure, 
indicating that subtle effects may have a strong influence, and it remains unclear as to how to maximise this parameter.

\section{CONCLUSIONS}

The coordination chemistry of uranyl ion with the asymmetric 1,2,4 isomer of benzenetricarboxylate has been extended by the generation of 11 uranyl ion complexes containing either organic countercations (phosphonium, protonated DABCO or quinuclidine), or additional cations $\left(\mathrm{Ag}^{+}, \mathrm{Rb}^{+}, \mathrm{Cs}^{+}, \mathrm{Ni}^{2+}\right.$ and $\mathrm{Cu}^{2+}$, the two latter being bound to the azamacrocycles cyclam or $R, S$-Me $\mathrm{Meyclam}_{6}$, respectively). These homo- or heterometallic complexes crystallize as mono-, di- or triperiodic coordination polymers, depending on the interplay of factors among which the three most obvious are the dihedral angles made by the carboxylate groups with the aromatic ring, the coordination mode of each carboxylate group, and the presence of bridging additional metal cations. As previously discussed, ${ }^{3,4}$ the orthogonal positioning with respect to the ring of one of the carboxylate groups in 1 and 2 positions, due to steric hindrance, favors the formation of triperiodic structures, but the presence of additional cations allows such frameworks to be formed even when no carboxylate group is orthogonal to the ring. The role of oxo bonding of the additional metal cations to uranyl is conspicuous in the present series, being found with $\mathrm{Ni}^{2+}, \mathrm{Ag}^{+}, \mathrm{Rb}^{+}$and $\mathrm{Cs}^{+}$, this bonding obviously providing an extension of the assembly along an axis perpendicular to the uranyl equatorial plane, and thus promoting triperiodic polymerization in most cases. The isomorphous triperiodic frameworks obtained with $\mathrm{Rb}^{+}$and $\mathrm{Cs}^{+}$present the peculiarity to contain a 2-fold interpenetrated triperiodic uranyl-only subunit. Overall, this ligand appears to be more versatile than its two congeners, the $1,3,5$ isomer, which is usually a planar ligand, and the 1,2,3 isomer, in which the central carboxylate group is orthogonal to the ring and to the lateral carboxylate groups. The 
photoluminescence properties of eight of the complexes were investigated and, except for the copper(II)-containing complex which is non-emissive, show uranyl emission spectra with the usual vibronic fine structure, in contrast to what has been previously observed with complexes containing oligonuclear uranium units. It is notable that one of the presently described complexes involving the $\mathrm{PPh}_{4}{ }^{+}$cation has a photoluminescence quantum yield of $35 \%$, one of the highest values measured in a uranyl carboxylate complex.

\section{ASSOCIATED CONTENT}

\section{Supporting Information}

The Supporting Information is available free of charge on the ACS Publications website at DOI: Table S1, Figures S1-S4 (PDF)

\section{Accession Codes}

CCDC 2013385-2013395 contain the supplementary crystallographic data for this paper. These data can be obtained free of charge via www.ccdc.cam.ac.uk/data_request/cif, or by emailing data_request@ccdc.cam.ac.uk, or by contacting The Cambridge Crystallographic Data Centre, 12 Union Road, Cambridge CB2 1EZ, UK; fax: +44 1223336033.

\section{AUTHOR INFORMATION}

\section{Corresponding Authors}

*E-mail: pierre.thuery@,cea.fr. (P.T.)

*E-mail: harrowfield@unistra.fr. (J.H.)

\section{ORCID}


Pierre Thuéry: 0000-0003-1683-570X

Youssef Atoini: 0000-0003-4851-3713

Jack Harrowfield: 0000-0003-4005-740X

\section{Notes}

The authors declare no competing financial interest.

\section{REFERENCES}

1. Burns, P. C. $\mathrm{U}^{6+}$ Minerals and Inorganic Compounds: Insights into an Expanded Structural Hierarchy of Crystal Structures. Can. Mineral. 2005, 43, 1839-1894.

2. Thuéry, P.; Harrowfield, J. Recent Advances in Structural Studies of Heterometallic UranylContaining Coordination Polymers and Polynuclear Closed Species. Dalton Trans. 2017, 46, $13660-13667$.

3. Liao, Z. L.; Li, G. D.; Wei, X.; Yu, Y.; Chen, J. S. Construction of Three-Dimensional UranylOrganic Frameworks with Benzenetricarboxylate Ligands. Eur. J. Inorg. Chem. 2010, 37803788.

4. Yusov, A. B.; Sokolova, M. N.; Grigor'ev, M. S.; Fedoseev, A. M.; Budantseva, N. A.; Moisy, P. Interaction of $\mathrm{U}(\mathrm{VI}), \mathrm{Np}(\mathrm{VI}), \mathrm{Pu}(\mathrm{VI})$, and $\mathrm{Np}(\mathrm{V})$ with Benzenetricarboxylic Acids: Complexation in Aqueous Solutions, Synthesis, and Crystal Structure of Uranyl Complexes $\left[\mathrm{UO}_{2}\left(\mathrm{H}_{2} \mathrm{O}\right)_{2}\left\{\mathrm{C}_{6} \mathrm{H}_{3}(\mathrm{COO})_{2}(\mathrm{COOH})\right\}\right]_{2} \cdot 2 \mathrm{H}_{2} \mathrm{O} \quad$ and $\quad\left[\left(\mathrm{UO}_{2}\right)_{3}\left(\mathrm{H}_{2} \mathrm{O}\right)_{4}\left\{\mathrm{C}_{6} \mathrm{H}_{3}(\mathrm{COO})_{3}\right\} 2\right]$. Radiochemistry 2012, 54, 105-114.

5. Borkowski, L. A.; Cahill, C. L. A Novel Uranium-Containing Coordination Polymer: Poly[[aqua(benzene-1,3,5-tricarboxylato)dioxouranium(VI)] Monohydrate]. Acta Crystallogr., Sect. E 2004, 60, m198-m200. 
6. Volkringer, C.; Mihalcea, I.; Vigier, J. F.; Beaurain, A.; Visseaux, M.; Loiseau, T. Metal-Organic-Framework-Type 1D-Channel Open Network of a Tetravalent Uranium Trimesate. Inorg. Chem. 2011, 50, 11865-11867.

7. Wang, Y.; Yin, X.; Liu, W.; Xie, J.; Chen, J.; Silver, M. A.; Sheng, D.; Chen, L.; Diwu, J.; Liu, N.; Chai, Z.; Albrecht-Schmitt, T. E.; Wang, S. Emergence of Uranium as a Distinct Metal Center for Building Intrinsic X-ray Scintillators. Angew. Chem. Int. Ed. 2018, 57, 7883-7887.

8. Groom, C. R.; Bruno, I. J.; Lightfoot, M. P.; Ward, S. C. The Cambridge Structural Database. Acta Crystallogr., Sect. B 2016, 72, 171-179.

9. Taylor, R.; Wood, P. A. A Million Crystal Structures: The Whole is Greater than the Sum of Its Parts. Chem. Rev. 2019, 119, 9427-9477.

10. Wang, K. X.; Chen, J. S. Extended Structures and Physicochemical Properties of UranylOrganic Compounds. Acc. Chem. Res. 2011, 44, 531-540.

11. Andrews, M. B.; Cahill, C. L. Uranyl Bearing Hybrid Materials: Synthesis, Speciation, and Solid-State Structures. Chem. Rev. 2013, 113, 1121-1136.

12. Loiseau, T.; Mihalcea, I.; Henry, N.; Volkringer, C. The Crystal Chemistry of Uranium Carboxylates. Coord. Chem. Rev. 2014, 266-267, 69-109.

13. Su, J.; Chen, J. S. MOFs of Uranium and the Actinides. Struct. Bond. 2015, 163, 265-296.

14. Zhang, Y.; Chen, L.; Guan, J.; Wang, X.; Wang, S.; Diwu, J. A Unique Uranyl Framework Containing Uranyl Pentamers as Secondary Building Units: Synthesis, Structure, and Spectroscopic Properties. Dalton Trans. 2020, 49, 3676-3679.

15. Surblé, S.; Serre, C.; Millange, F.; Férey, G. Structural Changes upon Dehydration of $\operatorname{Pr}^{(\mathrm{III})}(\mathrm{H} 2 \mathrm{O})\left\{\mathrm{C}_{6} \mathrm{H}_{3}-\left(\mathrm{CO}_{2}\right)_{3}\right\}$ or MIL-81: A New Three-dimensional Praseodymium 1,2,4Benzenetricarboxylate with a One Dimensional Inorganic Sub-network. Solid State Sci. 2006, $8,413-417$. 
16. Thuéry, P.; Atoini, Y.; Harrowfield, J. Uranyl-Organic Coordination Polymers with trans1,2-, trans-1,4-, and cis-1,4-Cyclohexanedicarboxylates: Effects of Bulky $\mathrm{PPh}_{4}{ }^{+}$and $\mathrm{PPh}_{3} \mathrm{Me}^{+}$ Counterions. Cryst. Growth Des. 2018, 18, 2609-2619.

17. Thuéry, P.; Harrowfield, J. $[\mathrm{Ni}(\text { cyclam })]^{2+}$ and $\left[\mathrm{Ni}\left(R, S \text {-Me}{ }_{6} \text { cyclam }\right)\right]^{2+}$ as Linkers or Counterions In Uranyl-Organic Species with cis- and trans-1,2-Cyclohexanedicarboxylate Ligands. Cryst. Growth Des. 2018, 18, 5512-5520.

18. Thuéry, P.; Atoini, Y.; Harrowfield, J. Counterion-Controlled Formation of an Octanuclear Uranyl Cage with cis-1,2-Cyclohexanedicarboxylate Ligands. Inorg. Chem. 2018, 57, 62836288.

19. Thuéry, P.; Atoini, Y.; Harrowfield, J. Structure-Directing Effects of Counterions in Uranyl Ion Complexes with Long-Chain Aliphatic $\alpha, \omega$-Dicarboxylates: 1D to Polycatenated 3D Species. Inorg. Chem. 2019, 58, 567-580.

20. Thuéry, P.; Atoini, Y.; Harrowfield, J. Uranyl Tricarballylate Triperiodic and Nanotubular Species. Counterion Control of Nanotube Diameter. Inorg. Chem. 2020, 59, 6953-6962.

21. Bruker AXS. APEX3 Crystallography Software Suite, Version 2019.1-0; Madison, Wisconsin, USA, 2019.

22. Hooft, R. W. W. COLLECT, Nonius BV: Delft, The Netherlands, 1998.

23. Bruker Nano, Inc. SAINT, Version 8.40A; Madison, Wisconsin, USA, 2019.

24. Otwinowski, Z.; Minor, W. Processing of X-Ray Diffraction Data Collected in Oscillation Mode. Methods Enzymol. 1997, 276, 307-326.

25. Bruker AXS. SADABS, Bruker/Siemens Area Detector Absorption and Other Corrections, Version 2016/2; Madison, Wisconsin, USA, 2016.

26. Krause, L.; Herbst-Irmer, R.; Sheldrick, G. M.; Stalke, D. Comparison of Silver and Molybdenum Microfocus X-Ray Sources for Single-Crystal Structure Determination. J. Appl. Crystallogr. 2015, 48, 3-10. 
27. Sheldrick, G. M. SHELXT - Integrated Space-Group and Crystal-Structure Determination. Acta Crystallogr., Sect. A 2015, 71, 3-8.

28. Sheldrick, G. M. Crystal Structure Refinement with SHELXL. Acta Crystallogr., Sect. C 2015, $71,3-8$.

29. Hübschle, C. B.; Sheldrick, G. M.; Dittrich, B. ShelXle: a Qt Graphical User Interface for SHELXL. J. Appl. Crystallogr. 2011, 44, 1281-1284.

30. Farrugia, L. J. WinGX and ORTEP for Windows: an Update. J. Appl. Crystallogr. 2012, 45, $849-854$.

31. Momma, K.; Izumi, F. VESTA 3 for Three-Dimensional Visualization of Crystal, Volumetric and Morphology Data. J. Appl. Crystallogr. 2011, 44, 1272-1276.

32. Blatov V. A.; Shevchenko, A. P.; Proserpio, D. M. Applied Topological Analysis of Crystal Structures with the Program Package ToposPro. Cryst. Growth Des. 2014, 14, 3576-3586.

33. Dance, I.; Scudder, M. Supramolecular Motifs: Concerted Multiple Phenyl Embraces between $\mathrm{Ph}_{4} \mathrm{P}^{+}$Cations are Attractive and Ubiquitous. Chem. Eur. J. 1996, 2, 481-486.

34. Spek, A. L. Structure Validation in Chemical Crystallography. Acta Crystallogr., Sect. D 2009, $65,148-155$.

35. Spackman, M. A.; Jayatilaka, D. Hirshfeld Surface Analysis. CrystEngComm 2009, 11, 1932.

36. Wolff, S. K.; Grimwood, D. J.; McKinnon, J. J.; Turner, M. J.; Jayatilaka, D.; Spackman, M. A. CrystalExplorer; University of Western Australia: Crawley, Australia, 2012.

37. Taylor, R.; Kennard, O. Crystallographic Evidence for the Existence of C-H $\cdots \mathrm{O}, \mathrm{C}-\mathrm{H} \cdots \mathrm{N}$, and C-H‥Cl Hydrogen Bonds. J. Am. Chem. Soc. 1982, 104, 5063-5070.

38. Desiraju, G. R. The C-H‥O Hydrogen Bond: Structural Implications and Supramolecular Design. Acc. Chem. Res. 1996, 29, 441-449. 
39. Etter, M. C.; MacDonald, J. C.; Bernstein, J. Graph-Set Analysis of Hydrogen-Bond Patterns in Organic Crystals. Acta Crystallogr., Sect. B 1990, 46, 256-262.

40. Bernstein, J.; Davis, R. E.; Shimoni, L.; Chang, N. L. Patterns in Hydrogen Bonding: Functionality and Graph Set Analysis in Crystals. Angew. Chem. Int. Ed. 1995, 34, 1555-1573. 41. Thuéry, P.; Harrowfield, J. Tetrahydrofurantetracarboxylic Acid: An Isomerizable Framework-Forming Ligand in Homo- and Heterometallic Complexes with $\mathrm{UO}_{2}{ }^{2+}, \mathrm{Ag}^{+}$, and $\mathrm{Pb}^{2+}$. Cryst. Growth Des. 2016, 16, 7083-7093.

42. Thuéry, P.; Atoini, Y.; Harrowfield, J. Favoring Framework Formation through StructureDirecting Effects in Uranyl Ion Complexes with 1,2,3,4-(Cyclo)butanetetracarboxylate Ligands. Cryst. Growth Des. 2019, 19, 4109-4120.

43. Adelani, P. O.; Albrecht-Schmitt, T. E. Differential Ion Exchange in Elliptical Uranyl Diphosphonate Nanotubules. Angew. Chem. Int. Ed. 2010, 49, 8909-8911.

44. Adelani, P. O.; Albrecht-Schmitt, T. E. Layered Uranyl Coordination Polymers Rigidly Pillared by Diphosphonates. Cryst. Growth Des. 2012, 12, 5800-5805.

45. Nelson, A. G. D.; Rak, Z.; Albrecht-Schmitt, T. E.; Becker, U.; Ewing, R. C. Three New Silver Uranyl Diphosphonates: Structures and Properties. Inorg. Chem. 2014, 53, 2787-2796.

46. Thuéry, P.; Harrowfield, J. Variations on the Honeycomb Topology: From Triangular- and Square-Grooved Networks to Tubular Assemblies in Uranyl Tricarballylate Complexes. Cryst. Growth Des. 2017, 17, 963-966.

47. Thuéry, P.; Harrowfield, J. $\mathrm{Ag}^{\mathrm{I}}$ and $\mathrm{Pb}^{\mathrm{II}}$ as Additional Assembling Cations in Uranyl Coordination Polymers and Frameworks. Cryst. Growth Des. 2017, 17, 2116-2130.

48. Mei, L.; Hu, K. Q.; Zhang, Z. H.; An, S. W.; Chai, Z. F.; Shi, W. Q. Stepwise ortho Chlorination of Carboxyl Groups for Promoting Structure Variance of Heterometallic Uranyl-Silver Coordination Polymers of Isonicotinate. Inorg. Chem. 2018, 57, 4673-4685. 
49. Locock, A. J.; Burns, P. C. Structures and Synthesis of Framework Rb and Cs Uranyl Arsenates and their Relationships with their Phosphate Analogues. J. Solid State Chem. 2003, 175, 372379.

50. Thuéry, P.; Masci, B. Synthesis and Crystal Structure of 1:2 Mixed Uranyl/Alkali Metal Ions $\left(\mathrm{Li}^{+}, \mathrm{Na}^{+}, \mathrm{K}^{+}, \mathrm{Cs}^{+}\right)$Complexes of p-tert-Butyltetrahomodioxacalix[4]arene. Dalton Trans. 2003, 2411-2417.

51. Thuéry, P.; Masci, B. A Bis(p-tert-butyloctahomotetraoxacalix[8]arene) Capsule with $\left[\left(\mathrm{UO}_{2}\right)_{2}(\mathrm{OH})_{2}\right]$ Links and a Disordered $\left[\mathrm{Rb}_{4}\left(\mathrm{H}_{2} \mathrm{O}\right)_{4}\right]$ Inner Core. Supramol. Chem. 2004, 16, $81-86$.

52. Giesting, P. A.; Porter, N. J.; Burns, P. C. A Series of Sheet-Structured Alkali Metal Uranyl Oxalate Hydrates: Structures and IR Spectra. Z. Kristallogr. 2006, 221, 589-599.

53. Masci, B.; Thuéry, P. Hydrothermal Synthesis of Uranyl-Organic Frameworks with Pyrazine2,3-dicarboxylate Linkers. CrystEngComm 2008, 10, 1082-1087.

54. Adelani, P. O.; Oliver, A. G.; Albrecht-Schmitt, T. E. Layered and Three-Dimensional Framework Cesium and Barium Uranyl Carboxyphenylphosphonates. Cryst. Growth Des. 2011, 11, 3072-3080.

55. Vologzhanina, A. V.; Savchenkov, A. V.; Dmitrienko, A. O.; Korlyukov, A. A.; Bushmarinov, I. S.; Pushkin, D. V.; Serezhkina, L. B. Electronic Structure of Cesium Butyratouranylate(VI) as Derived from DFT-assisted Powder X-ray Diffraction Data. J. Phys. Chem. A 2014, 118, 9745-9752.

56. Savchenkov, A. V.; Klepov, V. V.; Vologzhanina, A. V.; Serezhkina, L. B.; Pushkin, D. V.; Serezhkin, V. N. Trinuclear $\left\{\operatorname{Sr}\left[\mathrm{UO}_{2} \mathrm{~L}_{3}\right]_{2}\left(\mathrm{H}_{2} \mathrm{O}\right)_{4}\right\}$ and Pentanuclear $\left\{\mathrm{Sr}\left[\mathrm{UO}_{2} \mathrm{~L}_{3}\right]_{4}\right\}^{2-}$ Uranyl Monocarboxylate Complexes (L-acetate or $n$-butyrate Ion). CrystEngComm 2015, 17, 740-746. 
57. Thuéry, P.; Harrowfield, J. Tetrahedral and Cuboidal Clusters in Complexes of Uranyl and Alkali or Alkaline-Earth Metal Ions with rac- and (1R,2R)-trans-1,2Cyclohexanedicarboxylate. Cryst. Growth Des. 2017, 17, 2881-2892.

58. Kalaj, M.; Carter, K. P.; Savchenkov, A. V.; Pyrch, M. M.; Cahill, C. L. Syntheses, Structures, and Comparisons of Heterometallic Uranyl Iodobenzoates with Monovalent Cations. Inorg. Chem. 2017, 56, 9156-9168.

59. Liu, C.; Wang, C.; Sun, Z. M. Conformational 2-Fold Interpenetrated Uranyl Supramolecular Isomers Based on (6,3) Sheet Topology: Structure, Luminescence, and Ion Exchange. Inorg. Chem. 2018, 57, 15370-15378.

60. Blatov, V. A.; Carlucci, L.; Ciani, G.; Proserpio, D. M. Interpenetrating Metal-Organic and Inorganic 3D Networks: a Computer-Aided Systematic Investigation. Part I. Analysis of the Cambridge Structural Database. CrystEngComm 2004, 6, 377-395.

61. Thuéry, P.; Harrowfield, J. Structural Consequences of 1,4-Cyclohexanedicarboxylate Cis/Trans Isomerism in Uranyl Ion Complexes: From Molecular Species to 2D and 3D Entangled Nets. Inorg. Chem. 2017, 56, 13464-13481.

62. Liu, C.; Chen, F. Y.; Tian, H. R.; Ai, J.; Yang, W.; Pan, Q. J.; Sun, Z. M. Interpenetrated Uranyl-Organic Frameworks with bor and pts Topology: Structure, Spectroscopy, and Computation. Inorg. Chem. 2017, 56, 14147-14156.

63. Wang, S.; Mei, L.; Yu, J. P.; Hu, K. Q.; Liu, Z. R.; Chai, Z. F.; Shi, W. Q. Large-Pore Layered Networks, Polycatenated Frameworks, and Three-Dimensional Frameworks of Uranyl Tri(biphenyl)amine/Tri(phenyl)amine Tricarboxylate: Solvent-/Ligand-Dependent Dual Regulation. Cryst. Growth Des. 2018, 18, 4347-4356.

64. Zhao, R.; Mei, L.; Hu, K. Q.; Tian, M.; Chai, Z. F.; Shi, W. Q. Bimetallic Uranyl Organic Frameworks Supported by Transition-Metal-Ion-Based Metalloligand Motifs: Synthesis, Structure Diversity, and Luminescence Properties. Inorg. Chem. 2018, 57, 6084-6094. 
65. An, S. W.; Mei, L.; Hu, K. Q.; Li, F. Z.; Xia, C. Q.; Chai, Z. F.; Shi, W. Q. Bipyridine-Directed Syntheses of Uranyl Compounds Containing Semirigid Dicarboxylate Linkers: Diversity and Consistency in Uranyl Speciation. Inorg. Chem. 2019, 58, 6934-6945.

66. Thuéry, P.; Harrowfield, J. Uranyl Ion-Containing Polymeric Assemblies with cis/trans Isomers of 1,2-, 1,3-, and 1,4-Cyclohexanedicarboxylates, Including a Helical Chain and a 6-Fold-Interpenetrated Framework. Cryst. Growth Des. 2020, 20, 262-273.

67. Liang, L. L.; Zhang, R. L.; Zhao, J. S. Counterion-Controlled Formation of Layered Honeycomb and Polythreading Uranyl Networks and the Highly Sensitive and Selective Detection of $\mathrm{Fe}^{3+}$ in Aqueous Media. Inorg. Chem. 2020, 59, 7980-7990.

68. Alexandrov, E. V.; Blatov, V. A.; Kochetkov, A. V.; Proserpio, D. M. Underlying Nets in Three-Periodic Coordination Polymers: Topology, Taxonomy and Prediction from a ComputerAided Analysis of the Cambridge Structural Database. CrystEngComm, 2011, 13, 3947-3958.

69. Mihalcea, I.; Henry, N.; Loiseau, T. Revisiting the Uranyl-phthalate System: Isolation and Crystal Structures of Two Types of Uranyl-Organic Frameworks (UOF). Cryst. Growth Des. 2011, 11, 1940-1947.

70. Zachariasen, W. H.; Plettinger, H. A. Crystal Chemical Studies of the $5 f$-Series of Elements. XXV. The Crystal Structure of Sodium Uranyl Acetate. Acta Crystallogr. 1959, 12, 526-530.

71. Burrows, H. D.; Formosinho, S. J.; Miguel, M. da G.; Pinto Coelho, F. Quenching of the Luminescent State of the Uranyl Ion $\left(\mathrm{UO}_{2}{ }^{2+}\right)$ by Metal Ions. Evidence for an Electron Transfer Mechanism. J. Chem. Soc., Faraday Trans. 1 1976, 72, 163-171.

72. Kerr, A. T.; Cahill, C. L. Postsynthetic Rearrangement/Metalation as a Route to Bimetallic Uranyl Coordination Polymers: Syntheses, Structures, and Luminescence. Cryst. Growth Des. 2014, 14, 1914-1921. 
73. Kerr, A. T.; Cahill, C. L. CuPYDC Metalloligands and Postsynthetic Rearrangement/Metalation as Routes to Bimetallic Uranyl Containing Hybrid Materials: Syntheses, Structures, and Fluorescence. Cryst. Growth Des. 2014, 14, 4094-4103.

74. Ridenour, J. A.; Pyrch, M. M.; Manning, Z. J.; Bertke, J. A.; Cahill, C. L. Two Novel Bimetallic Transition Metal-Uranyl One-Dimensional Coordination Polymers with Manganese(II) and Cobalt(II) Incorporating Bridging Diglycolate (2,2'-oxydiacetate) Ligands. Acta Crystallogr., Sect. C 2017, 73, 588-592.

75. Kerr, A. T.; Ridenour, J. A.; Noring, A. A.; Cahill, C. L. Two Uranyl-Copper(II) Bimetallic Coordination Polymers Containing trans-3, 3(pyridyl)acrylic acid: Structural Variance through Synthetic Subtleties. Inorg. Chim. Acta 2019, 494, 204-210.

76. Gomez, G. E.; Ridenour, J. A.; Byrne, N. M.; Shevchenko, A. P.; Cahill, C. L. Novel Heterometallic Uranyl-Transition Metal Materials: Structure, Topology, and Solid State Photoluminescence Properties. Inorg. Chem. 2019, 58, 7243-7254.

77. Brachmann, A.; Geipel, G.; Bernhard, G.; Nitsche, H. Study of Uranyl(VI) Malonate Complexation by Time Resolved Laser-Induced Fluorescence Spectroscopy (TRLFS). Radiochim. Acta 2002, 90, 147-153.

78. Wang, L.; Tu, B.; Xu, W.; Fu, Y.; Zheng, Y. Uranyl Organic Framework as a Highly Selective and Sensitive Turn-on and Turn-off Luminescent Sensor for Dual Functional Detection Arginine and $\mathrm{MnO}_{4}^{-}$. Inorg. Chem. 2020, 59, 5004-5017.

79. Natrajan, L. S. Developments in the Photophysics and Photochemistry of Actinide Ions and their Coordination Compounds. Coord. Chem. Rev. 2012, 256, 1583-1603.

80. Thuéry, P.; Atoini, Y.; Harrowfield, J. Functionalized Aromatic Dicarboxylate Ligands in Uranyl-Organic Assemblies: The Cases of Carboxycinnamate and 1,2-/1,3Phenylenedioxydiacetate. Inorg. Chem. 2020, 59, 2923-2936. 
81. Thuéry, P.; Rivière, E.; Harrowfield, J. Uranyl and Uranyl-3d Block Cation Complexes with 1,3-Adamantanedicarboxylate: Crystal Structures, Luminescence and Magnetic Properties. Inorg. Chem. 2015, 54, 2838-2850.

82. Chorazy, S.; Zakrzewski, J. J.; Reczyński, M.; Sieklucka, B. Multi-Colour Uranyl Emission Efficiently Tuned by Hexacyanidometallates within Hybrid Coordination Frameworks. Chem. Commun. 2019, 55, 3057-3060.

83. Thuéry, P.; Atoini, Y.; Harrowfield, J. Chiral Discrete and Polymeric Uranyl Ion Complexes with $(1 R, 3 S)-(+)$-Camphorate Ligands: Counterion-Dependent Formation of a Hexanuclear Cage. Inorg. Chem. 2019, 58, 870-880.

84. Xie, J.; Wang, Y.; Liu, W.; Lin, X.; Chen, L.; Zou, Y.; Diwu, J.; Chai, Z.; Albrecht-Schmitt, T. E.; Liu, G.; Wang, S. Highly Sensitive Detection of Ionizing Radiations by a Photoluminescent Uranyl Organic Framework. Angew. Chem. Int. Ed. 2017, 56, 7500-7504.

85. Harrowfield, J.; Thuéry, P. Uranyl Ion Complexes of Polycarboxylates: Steps towards Isolated Photoactive Cavities. Chemistry 2020, 2, 63-79. 


\section{Isomerism in Benzenetricarboxylates: Variations in the Formation of Coordination Polymers with Uranyl Ion}

Pierre Thuéry, Youssef Atoini and Jack Harrowfield

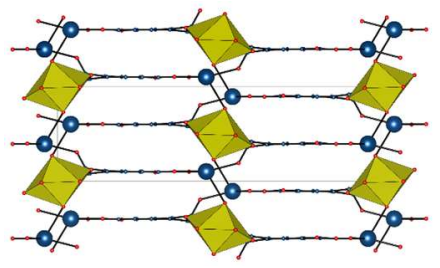

The asymmetric 1,2,4 isomer of benzenetricarboxylate complexes the uranyl cation with a variety of coordination modes, depending on the counterions and additional metal cations used, giving mono-, di- or triperiodic homo- or heterometallic coordination polymers, among which a triperiodic framework in which the uranyl-only subunit displays 2-fold interpenetration. 